\title{
Gender Wage Gaps, ‘Sticky Floors’ and 'Glass Ceilings’ in Europe
}

\author{
Louis N. Christofides* \\ Alexandros Polycarpou ${ }^{\ddagger}$ \\ Konstantinos Vrachimis ${ }^{\S}$
}

January 12, 2013

\begin{abstract}
We consider and attempt to understand the gender wage gap across 26 European countries, using 2007 data from the European Union Statistics on Income and Living Conditions. ${ }^{\#}$ The size of the gender wage gap varies considerably across countries, definitions of the gap, and selection-correction mechanisms. Most of the gap cannot be explained by the characteristics available in this data set. Quantile regressions show that, in a number of countries, the wage gap is wider at the top ('glass ceilings') and/or at the bottom of the wage distribution ('sticky floors'). We find larger mean/median gender gaps and more evidence of glass ceilings for full-time full-year employees, suggesting more female disadvantage in 'better' jobs. These features may be related to country-specific policies that cannot be evaluated at the individualcountry level, at a point in time. We use the cross-country variation in the unexplained wage gaps of this larger-than-usual sample of states to explore the influence of (i) country policies that reconcile work and family life and (ii) their wage-setting institutions. We find that country policies and institutions are related to features of their unexplained gender wage gaps in systematic, quantitatively important, ways.
\end{abstract}

JEL Classification: J16, J31, J50, C21

Keywords: gender wage gap, selection, quantiles, work-family reconciliation, wagesetting institutions

We thank participants at the "Mapping the Gender Equality: Research and Practices - The National and International Perspective" International Conference, UNESCO Chair in Gender Equality and Women's Empowerment, University of Cyprus, Cyprus, the Annual Meeting of Southern European Economic Theorists (ASSET) at the University of Evora, Portugal, 27-29 October 2011, and seminar participants at the University of Cyprus, for valuable comments and suggestions. We have also received comments and/or code from J. Albrecht, S. de la Rica, M. Frölich, E. Gautier, P. Van Kerm, B. Melly, B. Petrongolo, A. Van Vuuren, and two anonymous referees for which we are very grateful. The views expressed in this paper are the sole responsibility of the authors and should not be attributed to the Co-operative Central Bank of Cyprus, its Board of Directors or its Management.

*Corresponding author. Department of Economics, University of Cyprus, PO Box 20537, 1678 Nicosia, Cyprus. Phone: +35722893654, Fax: +357-22895021. E-mail: louis.christofides@ucy.ac.cy. http://www.econ.ucy.ac.cy/\%7Eeclouis/ Christofides is a Research Associate of CESifo and a Research Fellow of IZA.

${ }^{\ddagger}$ Department of Economics, University of Cyprus, PO Box 20537, 1678 Nicosia, Cyprus. Phone: +357-22893668, Fax: +35722892426. E-mail: polycarpou@ucy.ac.cy .http://alexandrospolycarpou.weebly.com/

$\S$ Department of Economics, University of Cyprus, PO Box 20537, 1678 Nicosia, Cyprus and Cooperative Central Bank of Cyprus. Phone: +357-22893695, Fax: +357-22892432. E-mail: vrachimis.kostantinos@ucy.ac.cy . http://vrachimis.weebly.com/ \#European Commission, Eurostat, cross-sectional EU SILC UDB 2007 - version 1 of March 2009. Eurostat has no responsibility for the results and conclusions of this paper. 


\section{Introduction}

Labour market disparities by gender have attracted considerable political and legislative attention. In the European Union (EU) alone, two different directives, the Racial Equality Directive and the Employment Framework Directive, define a set of principles that offer legal protection against discrimination. The EU Employment Guidelines, 2003/58/EC of July 22, 2003, indicate that "Member States will, through an integrated approach combining gender mainstreaming and specific policy actions, encourage female labour market participation and achieve a substantial reduction in gender gaps in employment rates, unemployment rates and pay by 2010”. In this paper we examine the gender pay gap across European countries which can be presumed to espouse the principle of gender equality.

While a number of important studies have addressed some of these issues for some European countries (see, inter alia, Albrecht et al (2003), Arulampalam et al (2007), de la Rica et al (2008), Olivetti and Petrongolo (2008), Albrecht et al (2009), and Nicodemo (2009)), this paper focuses on the mean and median unexplained gaps, 'sticky floors' and 'glass ceilings' that can be discerned in many more European countries and relates them in a more inclusive way to country-specific wage-setting institutions and policies that reconcile work and family life. To do this effectively, it is necessary to use the maximum number of countries available so as to achieve maximum variability in the institutional and policy settings. The 2007 EU Statistics on Income and Living Conditions (EU-SILC) dataset includes information on 24 of the 2007 EU countries (all except Malta) along with Iceland and Norway. This information is available on a consistent basis for all 26 countries, thereby making it possible to implement a common econometric protocol.

We explore the degree of success of the common set of conditioning variables available in EU-SILC in explaining the wage gaps of the 26 European countries, taking care to check and address possible selection issues in a number of ways. The benchmark Oaxaca and Ransom (1994) approach is used to decompose the average wage differences between the genders. The variation in the gender-wage gap across the wage distribution is examined using quantile regression analysis, following the methodology proposed by Melly (2005). This allows us to search for possible 'sticky 
floor' and 'glass ceiling' effects - see Albrecht et al (2003). With these gaps and effects established on a consistent basis across the 26 countries, we consider the extent to which they are related to various country policies and institutional features. The OECD (2001) Work-Family Reconciliation Index, initially covering 14 EU and OECD countries, is recreated for the 26 countries in our sample and is used, along with the Hierarchical Cluster Analysis of wage bargaining systems in Du Caju et al (2009), to examine the relationship between gender gaps and effects on the one hand and country features and policies on the other. A number of sensitivity checks produce results consistent with those found in the main body of the paper.

We find that the gender wage gap is positive and significant in all countries and that it often increases once selection is taken into account suggesting that female high earners are overrepresented in selected samples. Consistent with a number of studies, the bulk of the observed wage differences cannot be explained by observed characteristics. Industry and occupation controls are, in general, important determinants of wages and gender gaps but the coefficients associated with Public Administration and Defence are such that the gender wage gap in this sector is higher in some countries, lower in others and not significantly different from that in the private sector in most countries. The Melly (2005) quantile-based wage decompositions reveal the presence of 'glass ceiling' and 'sticky floor' effects in a number of countries. These indications of female disadvantage are stronger when attention is confined to full-time full-year jobs. Looking across the 26 countries, the unexplained part of the Oaxaca-Ransom (1994) average wage gap, the unexplained median wage gap and glass ceiling effects from Melly’s (2005) unexplained quantiles are systematically related to the work-family reconciliation policies and wage-setting institutions in these countries with effects which are quantitatively important.

The objective in this literature has largely been to ensure that gender-specific features of wage distributions, especially among countries which share and promote the objective of gender equality, cannot be attributed to unobserved characteristics and that unexplained effects relate truly to female disadvantage. Unfortunately, in singlecountry explorations with limited time and policy or institutional variation, countryspecific policies and institutions must remain an unobservable captured only by intercept differences among gender-specific wage equations. Some hope of narrowing 
down the unexplained effects exists when the experiences and policies in a large number of countries can be compared. Yet, international explorations run the risk of muddling possible gender disadvantage with data consistency problems and country differences in institutions and attitudes to gender issues. By focusing on a large set of countries with similar values and by using the same data and econometric protocols, we contribute to this important policy area by bringing to the fore the role of workfamily policies and wage-setting institutions as they vary across countries.

Section 2 notes studies that follow a broad sweep across European and other countries and provides background information on the gender wage gap. Section 3 describes the EU-SILC data used and section 4 the econometric methodology and the results obtained. Section 5 considers the relation between work-family reconciliation policies and wage-setting institutions to features of the wage gap. Section 6 concludes.

\section{The gender wage gap: A brief survey of the literature}

The literature on the gender gap is enormous. Here, attention is limited to studies with an explicit cross-country orientation; our review is indicative rather than exhaustive see also Kunze (2008). Plantenga and Remery (2006) examine the unconditional gender wage gap for 24 EU states (except Malta) plus Iceland, Liechtenstein and Norway and survey policies that aim to reduce this gap. Brainerd (2000) examines the gender wage gap in ex USSR republics. Weichselbaumer and Winter-Ebmer (2005), based on a meta-analysis of international gender wage gaps, conclude that between the 1960s and the 1990s unconditional differentials fell. They attribute this to improved education and training for women. Blau and Kahn (1996), using the Juhn et al (1991) decomposition, show that eight European countries have a lower gender gap than the US and attribute this to higher female wages for low earners in Europe. Blau and Kahn (2003) also argue that institutional settings affect the gender wage gap.

Olivetti and Petrongolo (2008) examine the non-randomness of selection into work and how this might affect international comparisons. They estimate median wage gaps in a sample of employed workers and also in a sample enlarged with the nonemployed - for whom wages are imputed. For most countries, the median wage gaps in imputed wage distributions are higher than those in the actual wage distributions, suggesting that female high earners are overrepresented in the workforce. 
Nicodemo (2009) examines the extent of the wage gap in France, Greece, Italy, Portugal and Spain in 2001 and 2006, using the EU-SILC and the European Community Household Panel Survey (ECHPS) datasets. She finds a positive wage gap in all countries and periods, most of which cannot be explained by observed characteristics. The gender gap is larger at the bottom of the distribution and smaller at the top in most countries in 2006.

Arulampalam et al (2007) examine the gender wage gap in Austria, Belgium, Great Britain, Denmark, Finland, France, Germany, Ireland, Italy, Netherlands and Spain using the ECHPS for the years 1995-2001. The gap widens toward the top of the wage distribution in most of countries and, in a few cases, it also widens at the bottom of the distribution. The authors use the OECD (2001) Work-Family Reconciliation Index to examine possible factors that affect the extent of the wage gap. They conclude that differences in work-family reconciliation policies and wage-setting institutions (proxied only by union membership rates) may account for the variation in wage gaps.

Despite the wealth of information and methodologies contained in these studies, a gap in the literature remains: No study has investigated, using similar data and protocols, the conditional gap across a large number of countries that share similar declared policies and examined the extent to which the unexplained gender gap and its features may be related to country-specific policies and institutions. Here, we attempt to fill this void using more recent data, a much larger set of European countries that hold similar values, the OECD Work-Family Reconciliation Index modified to apply to the 26 countries studied, and a much broader (following Du Caju et al (2009)) set of criteria to describe wage-setting institutions that may affect the gender wage gap.

\section{Data}

The data used for the econometric analysis is the 2007 EU-SILC, prepared conformably by the statistical services of the countries involved on behalf of Eurostat. Information is available for all EU countries (except Malta) but Norway and Iceland are also included in this data set. The EU-SILC reports a wealth of information on the personal characteristics of each individual. These include age, education, marital and immigrant status, number of children, and child care details. Also, it reports 
information on working status, whether an individual was working full time or part time, whether an individual was working on a permanent contract, income from nonemployment, firm size, the industry of employment and occupation. In addition, information on annual earnings and hours worked is available so that both annual and hourly rates of pay can be considered. In order to keep the length of this paper reasonable, we have placed explanatory and technical material and details on sensitivity analyses in an Appendix - available from the authors' web sites on page 1.

Beginning with the original-data base sample, in the working sample that we analyse we include only individuals who (i) are aged between 25 and 54, (ii) work as employees (employers, the self-employed, and family workers are excluded), and (iii) are not students or handicapped, have not retired, given up a business, or are doing compulsory military or community service. We also check behaviour in an alternative sample where individuals must, in addition, have worked full-time for the whole of the previous year (FTFY). We refer to this alternative sample as the FTFY sample for further details see the Appendix. ${ }^{1}$ The restrictions for the working sample bypass complications involving further education, preparation for retirement, and the truthful reporting of incomes and they produce a more homogeneous sample. The alternative FTFY sample forces comparisons between men and women who work full-year and full-time, bringing out (relative to the results in the working sample) nuances that arise from differences in behaviour regarding hours-of-work and the 'quality' of FTFY jobs. Important differences between results involving the working and FTFY samples are noted in the paper but full results involving the FTFY sample are relegated to the Appendix. Here, age is used as a proxy for experience because experience is not available for Denmark, Finland, Greece, Iceland, Hungary, Norway, Sweden, and the UK. Where it is available, it is not reported for all individuals.

Table 1 presents, by gender, the average unconditional annual and hourly earnings as well as the hours worked by country in the working and the FTFY samples. This is useful background information and a link with official studies which typically focus on unconditional gender gaps. In the working sample, the highest annual male and female earnings are received in Iceland $(€ 59,026)$ and Denmark $(€ 42,931)$,

\footnotetext{
${ }^{1}$ We include individuals who have a second job but do not treat them as separate, additional, observations because there is no information about occupation, industry, or firm size in secondary jobs.
} 
respectively, while the lowest for both genders are received in the Slovak Republic (€6,143 for men and €4,642 for women). The highest hourly male and female earnings are received in Denmark (€27.86 and €22.94 respectively), while the lowest hourly rates are received in the Slovak Republic (€2.87 for men and $€ 2.30$ for women). In the FTFY sample, the highest annual male and female earnings respectively are also received in Iceland $(€ 62,866)$ and Denmark $(€ 45,143)$, while the lowest for both genders are also received in the Slovak Republic (€6,291 for men and $€ 4,787$ for women). The highest hourly male and female earnings are also received in Denmark (€27.20 and €22.53 respectively), while the lowest hourly rates for both genders are received in the Slovak Republic (€2.88 and $€ 2.29$ respectively). Thus, the working and FTFY samples flag Denmark and Iceland at the top and the Slovak Republic at the bottom of the country wage income distribution and document the enormous differences in pay across Europe.

Individuals in the FTFY sample of 'better' jobs earn, on average, more than those in the working sample per annum. However, because hours of work ${ }^{2}$ are, on average, lower in the working sample, especially for women, hourly wages are often higher in the working sample: They are, on average, higher than in the FTFY sample in 15 countries for men and 22 countries for women. A question explored below is the relative performance of women in the working and FTFY sample of 'better' jobs. Our focus is on wage rates rather than the intensity of participation: We use ln hourly wages and gender gaps involving these, in both the working and in the FTFY samples.

Figure 1 presents the ln hourly unconditional wage gap by country in the working sample. The highest gaps are found in Cyprus and Estonia (0.370 and 0.359 respectively), followed by smaller gaps for the Czech Republic, Austria and the UK (0.270, 0.257 and 0.243 respectively), and much smaller gaps for the remaining countries, culminating with the 0.032 ln point gap for Belgium. Scandinavian countries have middling, while Italy and Spain have relatively low gaps. The average and median hourly gender wage gaps across the EU24, Iceland and Norway are 0.159

\footnotetext{
${ }^{2}$ In the working sample, the longest weekly hours worked are in Iceland for men (49.39) and in Germany and Latvia for women (40.91in both countries). The shortest hours worked are in the Netherlands for men (38.95) and Ireland for women (29.89). In the FTFY sample, the longest weekly hours worked are in Iceland (50.68 for men and 43.83 for women). The shortest hours worked are in the Netherlands (39.22 for men and 37.72 for women). In general, hours are shorter for men and much shorter for women in the working, rather than the FTFY, sample.
} 
and 0.148 ln-wage points respectively. Had Figure 1 been based on the FTFY sample (see the Appendix), the top three unconditional gaps would still have been claimed by Cyprus, Estonia and the Czech Republic (0.422, 0.373, and 0.266 respectively) while the bottom three would include Belgium, Portugal and Slovenia (0.092, 0.078, and 0.052 respectively). The general ranking of countries does change but, in 19 out of the 26 countries, the unconditional gap is larger in the FTFY sample, raising again the issue of whether the gender gap is larger for FTFY jobs.

\section{Econometric models and results obtained}

We begin by estimating Ordinary Least Squares (OLS) ln hourly earnings equations, by gender, which take account of relevant characteristics available in the EU-SILC data. When the Heckman $(1974,1979)$ corrections are implemented, we use additional variables relating to family circumstances and non-labour income which account for membership in the selected, working, sample. Appropriate sample adjustments are made when the Full Time Full Year (FTFY) sample is used instead. The mean difference between male and female earnings is decomposed, as per Oaxaca and Ransom (1994), into a portion attributable to characteristics and portions attributable to the 'male advantage' and the 'female disadvantage'. Since decompositions of mean differences do not allow for an examination of possible 'sticky floor' and 'glass ceiling' effects, Melly (2005) decompositions along quantiles of the wage distribution are also generated, addressing possible selection issues using the Van Kerm (2012) method. Some sensitivity analyses, explained in the Appendix, are noted along the way.

\subsection{The Oaxaca-Ransom decompositions}

The Oaxaca and Ransom (1994) decomposition is given by:

$$
\bar{W}^{M}-\bar{W}^{F}=\left(\bar{X}^{M}-\bar{X}^{F}\right) \hat{\beta}^{N}+\bar{X}^{M}\left(\hat{\beta}^{M}-\hat{\beta}^{N}\right)+\bar{X}^{F}\left(\hat{\beta}^{N}-\hat{\beta}^{F}\right)
$$

where $\bar{W}^{M}$ and $\bar{W}^{F}$ are the average values of ln hourly earnings for males and females, $\bar{X}^{M}$ and $\bar{X}^{F}$ are vectors with the average characteristics for the two genders and $\hat{\beta}^{M}$ and $\hat{\beta}^{F}$ are the OLS estimates of relevant coefficients. $\hat{\beta}^{N}$ is a nondiscriminatory coefficient structure obtained from the pooled regression of males and 
females. The first term in equation (1) measures the explained part, the second the male advantage and the third the female disadvantage. The sum of the second and third terms constitutes the unexplained component examined below.

Table 2 provides decomposition results based on equation (1). The set of explanatory variables in the wage equations includes a constant, age (25-34, 35-44, and 45-54), education (elementary to lower secondary, secondary, and higher), marital status (single, married, or divorced, separated, widowed), immigration status (immigrant, not immigrant), firm size (firm employs ten or less, or more than 10 individuals), employment status (permanent, temporary work), industry of employment (12 categories, including Public Administration and Defence), and occupation (10 categories). In the Oaxaca and Ransom (1994) decompositions, the 'normalize' option in Stata is used (coefficients then measure deviations from grand means) thereby avoiding the sensitivity of decomposition results to the choice of the omitted category. Also, in Table 2a below, where public/private sector comparisons are made, the devcon command in Stata is used to produce industry effects which are measured as deviations from grand means. Otherwise, when categorical variables are used, one class is omitted. Table 2 also includes results based on the Heckman $(1974,1979)$ selection corrections. To implement these corrections, the Probit equations include age, education, marital and immigrant status, occupation and, in addition, (i) the number of dependent children under 16 including dependents 17-25 who are studying or are in compulsory military service, (ii) child-care provisions (three kinds of paid options as well as care by relatives are distinguished), and (iii) income from property rents and financial assets. These additional variables, as well as the inherent nonlinearity of the Mill’s ratio from the non-linear Probit equation, aid identification.

By a property of OLS, the predicted total gap in column 1, Table 2, is equal to the actual gap appearing in Figure 1. Column 5, Table 2, reports the pay gap that is predicted to prevail once selection into the working sample is taken into account (the 'offered' gap) and, in most cases (Austria, Belgium, Cyprus, Estonia, France, Germany, Greece, Iceland, Ireland, Italy, Latvia, Luxembourg, Norway, the 
Netherlands, Portugal, the Slovak Republic, Spain, Sweden, and Europe) the selection-adjusted gap is even higher, suggesting that positive selection is at work. ${ }^{3}$

The explained part of the total (whether of the actual total in column 1, Table 2, or of the 'offered' one in column 5, Table 2) is smaller than the unexplained part (the sum of the male advantage and female disadvantage in equation (1)) for many countries. This suggests that the data available do not account for the behaviour of earnings well and/or that a substantial amount of female disadvantage may exist. In the case of Belgium, Greece, Hungary, Iceland, Italy, Luxembourg, Poland, Portugal, Slovenia and Spain (joined by France after selection correction), the explained portion is negative, suggesting that female characteristics are superior to male ones.

It is of interest to check whether the patterns described above also hold for the FTFY sample - further details appear in the Appendix. In the vast majority of countries (all but Austria, the Czech Republic, the Netherlands, Portugal, Slovenia, Spain and the UK without selection corrections and in the above countries plus Hungary, the Slovak Republic and Sweden with selection corrections), the total and offered wage gaps are larger in the FTFY sample than in the working sample of part-year employees and part-timers. In the case of no selection corrections, the unexplained component is greater in the FTFY than in the working sample in all but 6 countries (Denmark, Germany, Luxembourg, Norway, the Netherlands and Slovenia) and ties. When selection corrections are carried out, this is true for all but 14 countries (Belgium, Cyprus, the Czech Republic, Germany, Hungary, Latvia, Lithuania, Luxembourg, Norway, the Netherlands, the Slovak Republic, Slovenia, Spain and Sweden) and ties. The balance of this evidence, along with the unconditional data in Table 1, suggests that the hourly pay gap is generally larger for FTFY work. That is, women do relatively better in part-year part-time jobs than in the 'better' FTFY jobs.

One aspect of compensation that has attracted considerable attention is remuneration ${ }^{4}$ in the public sector; here, we are particularly interested in the gender dimension. The

\footnotetext{
${ }^{3}$ When the Olivetti and Petrongolo (2008) imputation methods are used to check our selection corrections, the selection-adjusted gaps are also higher than the unadjusted gaps and, in some cases, higher than the Heckman $(1974,1979)$ ones - see the Appendix.

${ }^{4}$ In some countries, generous retirement and other benefits form part of the public sector pay package but we are not able to take these dimensions into account using the EU SILC data.
} 
level of pay in the public sector may, in some countries, be higher (lower) than in the private sector. This may not apply evenly to the two genders with the result that the gender pay gap may be modified, relative to that prevailing in the private sector. Since the EU-SILC does not have a private/public sector identifier, the only industry classification that is unambiguously associated with the public sector is Public Administration and Defence - education and health care are often privately offered and cannot be assumed to come under public sector pay arrangements. As a result, the number of observations in many cells is too small for analyses by gender and sector. ${ }^{5}$

What is possible is to examine the quantitative significance of the public/private sector distinction for the decompositions above, taking into account the coefficient on the dummy variable that signifies employment in Public Administration and Defence. We note that the Heckman correction has no noteworthy quantitative impact on the results of particular interest (see the Appendix) and so we proceed to describe the results for the working sample without selection corrections in Table 2a.

In the working sample, country results may be grouped as follows: (i) Countries where at least one coefficient on Public Administration and Defence in the male or female wage equations (Table 2a, columns 8 and 9) is significantly different from the grand mean of the industry effects (at least at the 10\% level) and generates a lower gender wage gap in the public sector. This list includes Latvia and Lithuania, where the coefficient for females is positive and significant but the coefficient for males is not significantly different from zero, the Czech Republic, Germany, Greece, the Netherlands, and the United Kingdom, where both coefficients are significant and positive but the female one is larger and Belgium where the coefficient for females is not significantly different from zero but the coefficient for males is negative and significant. (ii) Countries where the pattern of coefficient significance is such that the gender wage gap is rendered higher in the public sector. These include Cyprus, Hungary, Ireland, Italy, Luxembourg, Poland, and Spain, where both coefficients are significant and positive but that for males is larger; countries such as Iceland and Portugal, where men enjoy a further advantage but the coefficient for women is not significantly different from zero; and Slovenia, where the coefficient for females is

\footnotetext{
${ }^{5}$ In Austria, Denmark, Finland, Iceland, Ireland, Luxembourg, Norway, Slovenia, Sweden and the Netherlands, observation numbers in some cells fall below 100. See the Appendix.
} 
negative and significant but the coefficient for males is not significantly different from zero. (iii) In the remaining countries the coefficients on Public Administration and Defence are not significantly different from the grand mean of the industry effects for either gender. Thus, in the working sample, ten countries have a higher female disadvantage in the public sector and eight countries have a smaller gender gap than is the case in their private sector. It should be noted that the contribution of the public sector dummy variable to the explained part of the decomposition (column 5, Table 2a) is small and not always positive or significant. This arises because the endowment effect takes into account both the number of men and women in the public sector as well as the size and sign of the non-discriminatory coefficient on the Public Administration and Defence variable - see equation (1).

In the FTFY sample, the number of countries for which the public sector is associated with a reduced gender gap is nine rather than eight (Belgium, Cyprus, Czech Republic, Greece, Italy, Latvia, Lithuania, the Netherlands, and United Kingdom) and the number of countries for which the public sector generates a larger disadvantage is ten as well (France, Germany, Hungary, Ireland, Luxembourg, Poland, Portugal, Slovak Republic, Slovenia, and Spain). This evidence is only marginally consistent with the view that the public sector tends to be more progressive where FTFY jobs are concerned. As in the working sample, the impact of the public sector identifier on the explained part of the decomposition is negligible.

These results may be modified in data sets where the education and health portions of the public sector can be properly identified and dealt with. In any case, the proportion of the wage gap explained by all characteristics remains low and it is necessary to explore whether the limited role attributed to the included explanatory variables holds equally along different points of the gender wage gap distributions. ${ }^{6}$

\footnotetext{
${ }^{6}$ When substantial gender differences in the support of characteristics exist, some of the Oaxaca and Ransom (1994) decompositions may mislead. Ñopo (2008) proposes a non-parametric alternative to the decompositions in Table 2 using matching comparisons. This methodology can highlight gender differences in the supports and provide information on the explained and unexplained pay gaps. The Ñopo (2008) decompositions (see the Appendix) are similar to the Oaxaca and Ransom (1994) decompositions in both the working and FTFY samples.
} 


\subsection{Quantile decompositions of the gender wage gap}

The quantile regression methodology (see Koenker and Bassett (1978) allows the characteristics of individuals to have different impacts at different points of the wage distribution; it consequently affects the implied decompositions at each point. This approach allows examination of 'glass ceiling' and 'sticky floor' phenomena. Decomposition procedures based on quantile regression have been proposed by Melly (2005), Machado and Mata (2005) and Gosling et al (2000). We follow Melly (2005) because his methodology overcomes the problem of crossing quantile curves and because of its efficiency properties (Fortin, Lemieux and Firpo (2011)). In earlier studies, the total wage gap is used to identify sticky floors and glass ceilings. We follow this approach for comparability in the descriptive Table 4 below, but base our econometric analysis on the unexplained components.

Melly (2005) decomposes the difference between male and female wages (the left hand side of equation (2)) into the three factors that appear on the right hand side of equation (2), namely the effect of differences in residuals, in (median) coefficients, and in covariates (the explained component):

$$
\begin{aligned}
\hat{q}\left(\hat{\beta}^{M}, X^{M}\right)-\hat{q}\left(\hat{\beta}^{F}, X^{F}\right)= & {\left[\hat{q}\left(\hat{\beta}^{M}, X^{M}\right)-\hat{q}\left(\hat{\beta}^{m M, r F}, X^{M}\right)\right]+} \\
& {\left[\hat{q}\left(\hat{\beta}^{m M, r F}, X^{M}\right)-\hat{q}\left(\hat{\beta}^{F}, X^{M}\right)\right]+} \\
& {\left[\hat{q}\left(\hat{\beta}^{F}, X^{M}\right)-\hat{q}\left(\hat{\beta}^{F}, X^{F}\right)\right] }
\end{aligned}
$$

where and $X^{M}$ and $X^{F}$ are vectors with male and female characteristics, $\hat{\beta}^{M}$ and $\hat{\beta}^{F}$ are the estimated median coefficients on characteristics, $\hat{q}\left(\hat{\beta}^{F}, X^{M}\right)$ is the counterfactual earnings distribution of individuals with characteristics $X^{M}$ and coefficients $\hat{\beta}^{F}$, and $\hat{q}\left(\hat{\beta}^{m M, r F}, X^{M}\right)$ is the distribution that would have prevailed if the median coefficients were the same for males and females but the residuals were distributed as in the female distribution. The set of personal characteristics included are the same as in section 4.1. ${ }^{7}$ The decomposition results appear in Table 3 and our

\footnotetext{
${ }^{7}$ Some of the industries and occupations were merged because participation in these was very low for some of the countries and the decompositions could not have been performed if these near-singleton dummy variables were included in the estimation. More specifically armed forces employees were joined with professionals for Austria, Belgium, Denmark, Germany, France, Iceland, Ireland, Latvia,
} 
findings on sticky floor and glass ceiling effects are summarised in Table 4. Figure 2 presents, by country, decompositions over the male and female earnings distributions.

Table 3 reports the quantile regression decompositions obtained for five quantiles (10\%, 25\%, 50\%, 75\%, and 90\%). The part of the observed wage gap (not adjusted for selection - see below) that is not explained by observed characteristics (i.e. the sum of the first two terms in equation (2)) is shown in square brackets. The last two columns of Table 3 repeat information from Table 2 to provide a comparison between the median quantile and the Oaxaca and Ransom (1994) mean decomposition.

When the total and the unexplained gaps at the $50^{\text {th }}$ percentile of the quantile regression decompositions are compared to the mean values in the Oaxaca and Ransom (1994) decompositions, many more countries have unexplained components that exceed the total wage gaps. Only in the case of Austria, Estonia and the UK does the total gap exceed the unexplained gap for all quantiles. Thus, the quantile results reinforce the conclusion in the Oaxaca and Ransom (1994) decompositions that a substantial portion of the earnings gap remains unexplained. As in the Oaxaca and Ransom (1994) results, the quantile decompositions continue to show six new EU member states with some of the highest unconditional gender gaps (i.e. Cyprus, the Czech Republic, Estonia, Latvia, Lithuania, and the Slovak Republic in Figure 1) at the top of the median unexplained gap league, joined now by Greece, Iceland, Poland, and Portugal. The new EU countries near the bottom of the unconditional gap list (i.e. Hungary and Slovenia in Figure 1) are now placed higher in the median unexplained gap ranking of Table 3 (0.189 and 0.196 respectively). Consistent with the unconditional ranking in Figure 1, the lowest median unexplained gap is found in Belgium (0.105 in Table 3).

When the FTFY sample is used to construct a table parallel to Table 3 (see the Appendix), the results obtained are broadly similar. Cyprus tops the list of the median unexplained gap (0.369) and Belgium is still at the bottom (0.097). Only for Estonia is the total gap larger than the unexplained gap for every quantile. Despite this, the

Lithuania, Luxembourg, the Netherlands, the Slovak Republic, Slovenia, Sweden and the United Kingdom. Agriculture, fishing and mining employees were combined with craft workers for Belgium, and Luxembourg, Agriculture and the construction sector were merged in Belgium. In Denmark all employees work under permanent contracts and this variable is excluded from the estimation. 
overwhelming majority of countries (19) have a 90\% quantile unexplained component that is larger than that obtained for the part-year part-timers of Table 3. This is consistent with our earlier observation that women do relatively worse in the FTFY than in the unrestricted sample.

Sticky floor and a glass ceiling effects can be defined to exist if the $10^{\text {th }}$ percentile and the $90^{\text {th }}$ percentile of the total line in Figure 2, respectively, exceed other reference points of the wage distribution by at least two percentage points - see Table 4 for further details. Table 4 (ignore the stars for the moment) shows evidence of sticky floors in 12 countries: 10 out of the 26 countries in the sample when using the 10-25 difference and 10, not identical, countries when using the 10-50 difference. The strongest evidence for sticky floors is found in Cyprus, France, Italy, Luxembourg, Slovenia, and Sweden, where differences for all three reference points can be seen. This phenomenon for Cyprus and Luxembourg can be partly attributed to the high segregation of women in low-paying industries and occupations - see the Appendix.

A number (11) of countries exhibit significant glass ceiling effects. In Table 4, 6 countries (Denmark, Germany, Hungary, the Netherlands, Norway, and the Slovak Republic) satisfy all three reference standards and 5 other countries (Czech Republic, Finland, Iceland, Slovenia, and the UK) meet one of the three criteria. The remaining 15 countries do not exhibit glass ceiling effects based on any of the three measures used. The absence of sticky floors or glass ceilings for Greece and Spain conforms with findings in Olivetti and Petrongolo (2008) who argue for an extreme form of positive selection in these countries (only the most highly qualified and paid women enter the labour market). Table 4 also summarises the general shape of the total lnearnings distributions, displayed in Figure 2.

When Table 4 is constructed using the FTFY sample (see the Appendix Table 4A), the number of countries displaying some sticky floor behaviour is also 12. Belgium drops out but now Spain is added. Cyprus, Luxembourg, and Sweden continue to meet all criteria and to this list is now added Spain. In general, the overall impression on sticky floors is very comparable to that of Table 4 . However, the picture for glass ceilings is quite different. Instead of 11 countries displaying some effects, that number is now 21. There are 16 countries (rather than 6 in Table 4) that display glass ceilings 
by all criteria. As in Table 4, only Cyprus, Estonia, Lithuania, Portugal and Spain do not display any glass ceiling behaviour (in Table 4 this list included, in addition, Austria, Belgium, France, Greece, Italy, Ireland, Latvia, Luxembourg, Poland, and Sweden). The glass ceiling prevalence in the FTFY sample is consistent with the view that women are more likely to be disadvantaged in FTFY positions, especially when they are high-paying ones.

The stars in columns 2, 3, 5, and 6 of Table 4 indicate (i) glass ceiling effects where the $90^{\text {th }}$ percentile minus 1.96 times the standard error (i.e. a low upper bound) exceeds the reference gap plus 1.96 times the standard error (i.e. a high lower bound) or (ii) sticky floor effects where the $10^{\text {th }}$ percentile minus 1.96 times the standard error (i.e. a low lower bound) exceeds the reference gap plus 1.96 times the standard error (i.e. a high upper bound). This definition offers an alternative to the criterion of the two percentage points used in the literature. There are now far fewer starred effects, with Cyprus, France, Italy, Luxembourg and Sweden leading in sticky floors Slovenia carries a star in the 10-50 difference. As far as glass ceilings are concerned, Germany, the Netherlands, and Norway are the only ones with a star (in the 90-50 difference). The pattern of stars in the FTFY sample is consistent with the picture in Table 4 and suggests more female disadvantage in FTFY positions.

The shape of the wage gap distributions is examined more conveniently in Figure 2. The (blue) solid lines plot the total wage gap distribution, the (red) dotted lines show the explained component and the (green) dashed/dotted lines indicate the unexplained component. Since our econometric investigation of country policies and institutions below concerns behaviour which is not explained by the conditioning variables, our discussion now shifts to the unexplained dashed/dotted lines of Figure 2. The unexplained wage distribution follows five broad patterns. It is mainly U-shaped (the unexplained component is generally high at the extreme ends of the distribution, suggesting sticky floor and glass ceiling effects) in Denmark, Luxembourg, Norway and the Netherlands. The unexplained gap has a mainly inverse U-shape (little evidence of sticky floor or glass ceiling effects) in Austria, Cyprus, Germany, Greece, Latvia, Lithuania, Portugal, Slovenia and Spain. It has a mainly decreasing pattern (sticky floor effects only) in Belgium, France and Sweden. The unexplained portion 
has a mostly increasing pattern (glass ceiling effects only) in Estonia, Finland, Hungary, Italy and Poland. The remaining 5 countries display more complex patterns.

The FTFY Figure 2A in the Appendix, shows shapes that are U-shaped in 6 (rather than 4) countries, inverse U-shaped in 5 (rather than 9) countries, have a decreasing shape in 5 (rather than 3) countries, an increasing shape in 5 (rather than 5) countries and a complex pattern in 5 (rather than 5) countries. As the parallel discussion of Table 4 suggested, there is now more evidence for glass ceiling effects (U-shaped plus increasing patterns in 11 rather than 9 countries) and more evidence of sticky floors (U-shaped plus decreasing pattern in 11 rather than 9 countries).

The quantile decompositions by Melly (2005) do not account for selection into paid employment. To that end, we use the approach in Van Kerm (2012), which calculates the total wage gap at different quantiles in the presence of covariates and under endogenous labour market participation. ${ }^{8}$ We compare the quantiles of the Van Kerm (2012) total wage gap to those in the Melly (2005)-based Table 3. Under the Van Kerm (2012) procedures, for the working, unrestricted, sample, the general pattern in the vast majority of countries is for the corrected gender gap quantiles to be all larger than all the corresponding Melly (2005) ones. Exceptions are Cyprus, Estonia, Hungary, Italy, Latvia, Lithuania, Portugal, the Slovak Republic and Sweden where, for some of the lower quantiles, this does not hold. The shape of the distribution of the total wage gap, apart from the upward shift, remains the same or is reasonably similar in many countries. Exceptions are Cyprus, the Czech Republic, Germany, Hungary, Latvia, the Netherlands, Poland, Portugal, Slovenia, the UK and Iceland. The correlation coefficient between the total wage gap in Melly and in Van Kerm at the $10 \%, 25 \%, 50 \%, 75 \%$ and $90 \%$ quantiles is (p values in parentheses) $40.44(0.041)$, 40.31 (0.041), 50.45 (0.009), 51.64 (0.007) and 36.66 (0.066) respectively - see Supplementary Table 7 in the Appendix. We conclude that the Van Kerm (2012) selection corrections produce results which are similar to the Melly (2005) ones. Since

\footnotetext{
${ }^{8}$ The framework is parametric and involves the choice of the Singh and Maddala (1976) distribution with covariates (following Biewen and Jenkins (2005)) in a classic participation probability model and a copula function to model the association between participation and wages (Smith (2003)). We also examined the methodology proposed by Huber and Melly (2011) to see if selection issues are relevant to our sample but were unable to obtain results for many countries.
} 
the Van Kerm methodology does not decompose the selection-adjusted wage gap into explained and unexplained components, we proceed using the Melly results. ${ }^{9}$

The central tendency and other features of the gender wage gap distributions should be examined in the context of the willingness (given family responsibilities and family-related government policies) and ability (given the institutions of the labour market) of women to establish and maintain a continued presence in the labour market. Section 5 sheds some light on these issues by focussing on the association between gender pay gap features on the one hand and work-family reconciliation policies and labour market institutions on the other.

\section{The role of institutions and work-family reconciliation policies}

The extensive literatures on the role of (i) work-family reconciliation policies and (ii) labour market institutions on labour market outcomes contain a prima facie case for considering a possible connection to the gender wage gap. Many studies consider the influence of low-cost and family-friendly policies on female participation and employment and find beneficial effects. ${ }^{10}$ The availability of part-time work is often found to help the induction to (and maintenance of) female employment ${ }^{11}$, as are policies which reward motherhood. ${ }^{12}$ Maternity leave policies have complex effects. Extended maternity leave may increase out-of-work time and returning employees may receive reduced wage growth, resulting in a higher wage gap. On the other hand, maternity leave provisions may help preserve the ties of employees with their firms, increasing incentives to invest in human capital and leading to a lower wage gap. Such effects may hold with different force at different points of the wage distribution. Datta Gupta et al (2008) and Beblo and Wolf (2002) note that protracted maternity leave may affect wages adversely but Waldfogel (1998) reaches the opposite conclusion. Ruhm (1998) indicates that, although parental leave is associated with increases in female employment rates, if it is taken over extended periods it may

\footnotetext{
${ }^{9}$ The Van Kerm (2012) selection-corrected quantile values for the total wage distribution are generally larger in the Full Time Full Year (FTFY) than in the working sample (except for Cyprus, Estonia, Germany, Hungary, Luxembourg, the Slovak Republic and Slovenia, where three or more of the five quantiles are smaller in the FTFY than in the working sample) but the correlations between the Melly and Van Kerm totals are less tight (see the Supplementary Table 7A in the Appendix).

${ }^{10}$ See, inter alia, Del Boca and Vuri (2007), Gustafsson and Stafford (1992), and Viitanen (2005).

${ }^{11}$ See, for example, Kenjoh (2005).

${ }^{12}$ See Sanchez and Sanchez (2008).
} 
reduce the relative wage of female employees. Gutierrez-Domenech (2005) concludes that extended maternity leaves compromise the ability to re-enter the labour market.

Also extensive is the literature on the relationship and possible impact of labour market institutions on the gender gap. Countries with higher unionization rates tend to have lower wage dispersion (Blau and Kahn (1992) and Blau and Kahn (1996)), possibly lowering the wage gap. On the other hand, unions may be less likely to represent the interests of women effectively if they are perceived to have less attachment to the labour market - Booth and Francesconi (2003). They may also be less sensitive to the interests of members at the low end of the wage distribution - see also Arulampalam et al (2007).

Despite these important studies, the relationship between work-family reconciliation policies and labour market institutions on the one hand and gender gap features on the other needs to be re-examined using a large enough number of countries, with similar values, data, and econometric protocols. The relationship between the unexplained part of the mean (columns 3 plus 4, Table 2), the unexplained part of the median (column 6, Table 3), the sticky floors and the glass ceilings on the one hand and, on the other hand, the work-family reconciliation policies and wage-setting institutions prevailing in the countries studied is now considered.

The OECD (2001) Work-Family Reconciliation Index is a convenient summary of policies on work-family issues. The original measure used five variables which are not all available for our 26 countries and so we have constructed a close substitute based on (i) the availability of formal child care for children under 3 for more than 30 hours a week, (ii) maternity pay entitlement (the product of length and generosity), (iii) the extent to which part-time employment for family, children and other reasons is possible, (iv) the extent to which working times can be adjusted for family reasons and (v) the extent to which whole days of leave can be obtained without loss of holiday entitlement for family reasons. The data used to produce our composite Index (similar to the OECD data ${ }^{13}$ ), and the Index itself, appear in Table 5. For reasons to be

\footnotetext{
13 The correlation coefficient between the index for the fourteen EU countries included in OECD (2001) and our own composite index is $64 \%$ and it is significant at the $5 \%$ level.
} 
explained below, we also construct and use I4 (the sum of columns 1, 3, 4 and 5, in Table 5), which excludes the Maternity Pay Entitlements column.

The trade union membership rate is often used as a proxy for the wage-setting environment in each country. While useful, this may be too restrictive when a large number of countries are being studied. Du Caju et al (2009) process information on trade union density, extension procedures, the coverage of collective agreements, the existing and most dominant levels of wage bargaining, the existence of opening clauses, the types of coordination, government involvement in wage setting, the average agreement length, the existence of a minimum wage, and indexation arrangements for 2006 (the year prior to our data) to group 23 of our 26 countries into 'Largely Unregulated’ or LU (Czech Republic, Estonia, Hungary, Lithuania, Poland, and United Kingdom), 'Broadly Regulated' or BR (Austria, Denmark, France, Germany, Greece, Ireland, Italy, Netherlands, Norway, Portugal, and Sweden), and 'Highly Regulated' or HR (Belgium, Cyprus, Finland, Luxembourg, Slovenia, and Spain), using Hierarchical Cluster Analysis - see the last column of Table 5. Not included are Iceland, Latvia and the Slovak Republic.

The four parts of Figure 3 present, for the working sample, the relationship between (i) the mean unexplained gender wage gap, (ii) the median unexplained gender wage gap, (iii) glass-ceiling effects and (iv) sticky floor effects on the one hand and our own family-work reconciliation Index on the other. For the purposes of this analysis and, given that the median itself may be conditioned by country characteristics (i.e. family policies and labour market institutions), we consider the extent to which the $90^{\text {th }}$ and $10^{\text {th }}$ percentiles of the unexplained gender gap are themselves related to our index - rather than their difference from the median. The top two graphs within Figure 3 show that, across the 26 countries, the unexplained parts of the mean and median wage gap are negatively and significantly related ${ }^{14}$ to the work-family reconciliation index. That is, countries with generous work-family reconciliation policies (e.g. Denmark and the Netherlands when the Composite Index of Table 5 is used) tend to have an unexplained gender wage gap distribution whose central

\footnotetext{
${ }^{14}$ For the mean, the slope is -0.005 (standard error of 0.002 ) and for the median the slope is -0.015 (standard error of 0.004); the 5\% critical t value for 24 degrees of freedom in a two-tailed test is 2.064 . The results are based on regressions of the unexplained mean and median gaps on Composite Index.
} 
tendency is lower compared to countries with less generous policies (e.g. Cyprus, Poland and the Slovak Republic). The $90^{\text {th }}$ percentile is negatively and, at the $5 \%$ level, significantly (slope of -0.007 with a standard error of 0.003 ) related to our Index, but the $10^{\text {th }}$ quantile is not (slope of 0.001 with a standard error of 0.005 ). The lack of association at the low end of the distribution may be because more generous work-family reconciliation policies may stimulate the labour force participation of low-skill women, depressing their wages.

The results for the FTFY sample are even stronger - see the Appendix. The mean and median of the unexplained wage gap distribution are negatively and significantly related to our work-family reconciliation Index. For the mean, the slope is -0.007 (0.002) while, for the median, the slope is $-0.018(0.003)$. The $90^{\text {th }}$ quantile also has a negative, significant, slope of $-0.011(0.004)$, but the $10^{\text {th }}$ quantile continues not to be significantly related to the Index (slope of 0.001 with a standard error of 0.006). Thus, there appears to be strong evidence that better work-family reconciliation policies reduce the central tendency of the unexplained gender wage gap, that this relationship is stronger for FTFY employees and that it also holds at the top but not at the bottom of the unexplained gender wage gap distribution.

The median effects are explored more fully in Table 6. They present, for the working sample, the results of OLS regressions of the unexplained part of the Melly (2005) median gap on the constituent indices as well as our Composite Index. Given that Figure 3 suggests that the Oaxaca and Ransom (1994) average and the Melly (2005) median gender gap behave similarly, we present results only for the latter. The relationship between the unexplained median gap and the Composite Index of graph 2 in Figure 3 appears in column 6, Table 6. The relationship for the five constituent indices is individually negative and significant at least at the $5 \%$ level except for the Maternity Pay Entitlement (Maternity for short) variable which has a positive sign, significant at the $10 \%$ level. It would appear that very generous and extended maternity leaves may have an unintended impact on the unexplained median gender gap. For this reason, we enter the Maternity variable separately and include the I4 index for the four variables that carry similar coefficients in Table 6. In column 7, Table 6, the Maternity variable continues to have a positive, not significantly different from zero coefficient, and I4 now has the algebraically larger coefficient of -0.017 
(0.004). These results confirm the message in Figure 3 but show that it is not driven by the Maternity variable.

We now turn to the possible relation between wage-setting institutions and the median gender gap. A regression (using the 23 countries in Du Caju et al (2009)) of the unexplained Melly (2005) median on the three dummy variables signifying membership in the categories LU, BR and HR (without an intercept, as in column 8, Table 6, so that each coefficient also captures constant influences on the unexplained median gap) suggests that countries with a Largely Unregulated labour market have the highest median gender gap. Column 9, Table 6, asks whether the coefficient on LU is significantly higher than that on the omitted classes (BR and HR) and this is indeed the case - the coefficient on LU is 0.080 (0.036). Since work-family reconciliation policies have already been shown to be related to the unexplained gender gap across countries, we add LU to the equation of column 7, Table 6, realising that the influence of labour market institutions as captured by BR and HR is already included in the equation intercept. Column 10, Table 6 shows that LU is not statistically significant, suggesting that, when the influence of work-family reconciliation policies is taken into account, the largely unregulated sector is not associated with a further increase in the median gender gap.

Table 7 presents a similar analysis for the unexplained portion of the $90^{\text {th }}$ Melly (2005) quantile. The results are qualitatively similar to those for the unexplained median gap in Table 6 but they are somewhat weaker. The I4 index exerts a negative, statistically significant influence (coefficient of -0.008 and standard error of 0.003 ) on the $90^{\text {th }}$ quantile. The three labour institutions dummy variables LU, BR and HR continue (column 8, Table 7) to have coefficients which are positive and of a size that suggests that largely unregulated labour markets are associated with a larger value of the $90^{\text {th }}$ quantile than those with some degree of regulation. This is indeed confirmed at the $5 \%$ level in column 9 , Table 7 . In the case of the $90^{\text {th }}$ quantile, the combination of work-family reconciliation and labour market variables works best when the HR dummy variable is retained; it has the expected negative coefficient, significant at $1 \%$.

The results in Tables 6 and 7 suggest that, with the exception of the Maternity variable, work-family reconciliation policies and more regulation of labour markets 
are associated with lower values of the unexplained $50^{\text {th }}$ and $90^{\text {th }}$ quantiles. How important are these effects quantitatively? The highest I4 value is for Denmark (6.45, Table 5). The country with the lowest I4 value is Poland (-4.43, Table 5). In column 10, Table 6 , the coefficient on I4 is -0.017 and this suggests that if, ceteris paribus, Poland had Denmark's work-family reconciliation policies its unexplained median gap would have been lower by $0.185(-0.017 x 10.88) \ln$ wage points. Since, in Figure 1 , the median ln gender wage gap across the 26 countries is 0.148 , this is a substantial effect which would reposition a country with a higher-than-median wage gap to the lowest point of the gender gap league. This is, of course, an extreme example that explores the limits of the expected quantitative effects. The influence of labour market institutions is harder to assess because the effects in column 8, Table 6, cannot be easily separated from the true constant. However, the difference between a highly regulated and a largely unregulated country would be (column 10, Table 6) of the order of 0.009 ln wage points, or about $1 \%$.

At the $90^{\text {th }}$ quantile, the effects are smaller for work-family reconciliation policies ($0.006 \times 10.88=-0.065$, as opposed to -0.185 for the median) but larger for labour market institutions: The $90^{\text {th }}$ quantile of the unexplained ln wage gap in a highly regulated country would be lower by 0.066 ln wage points, or about $7 \%$.

In the FTFY sample, the results for the median are generally similar with our findings in Table 6 above. The Maternity variable still carries a positive coefficient in columns analogous to 2, 7 and 10, Table 6 , but it is never significantly positive. This may be because, in the 'better' FTFY jobs, these policies may not be as inimical to personal growth as in more partial forms of employment. The coefficients on LU, BR and HR in the column analogous to column 8, Table 6, are larger and, respectively, 0.285 (0.029), $0.184(0.022)$ and $0.211(0.035)$. Our results in the column analogous to column 10, Table 6, suggest coefficients for I4 and LU which are marginally larger in absolute value $(-0.019$ (0.006) and 0.020 (0.040), respectively). The results for the $90^{\text {th }}$ quantile in the FTFY sample are qualitatively similar but also larger in absolute terms and much stronger statistically than those in Table 7. For instance, in the final column 10, the coefficient on I4 is $-0.009(0.003)$ and that on HR $-0.070(0.023)$, both statistically significant. This suggests that the influence of policies is larger at the $90^{\text {th }}$ quantile in the FTFY sample than in the working sample. Thus, work-family 
reconciliation and labour market institutions and policies are associated more strongly with the $50^{\text {th }}$ and $90^{\text {th }}$ unexplained gender gap quantiles in the FTFY sample than in the working sample. The counterfactual estimates presented above would be somewhat stronger in the FTFY sample than in the working sample: For the median, the family policies effect would be $-0.207(-0.019 \times 10.88)$ while the largely unregulated effect would be 0.020 . For the $90^{\text {th }}$ quantile, the family policies effect would be $0.098(-0.009 x 10.88)$ while a country with a highly regulated labour market would have a ln wage gap which is lower by 0.070 ln wage points. These counterfactual estimates cannot be taken literally, of course, but they are indicative of the importance of policies and institutions.

The analysis in this section provides evidence that, beyond personal and employment characteristics, work-family reconciliation and wage-setting policies and institutions have predictable effects on gender wage gap outcomes and reduce the degree of ignorance embodied in the unexplained components of decompositions both at the median and at the $90^{\text {th }}$ quantile. These findings are a major payoff of the cross-country approach adopted here since they cannot emerge from single-country studies, may not be reliably estimated in studies involving a small number of countries, and would not be useful when data protocols are not standardised.

\section{Conclusion}

Using data from the 2007 EU-SILC, the gender wage gap is examined for a set of 26 European countries (all 2007 member states but Malta, along with Iceland and Norway). The hourly unconditional gender wage gap in the working sample where the FTFY restriction is not imposed varies considerably across countries, ranging from 0.370 ln-wage points in Cyprus to 0.032 ln-wage points in Belgium. The median ln wage gap for the 26 country distribution is 0.148 , or approximately $15 \%$.

Our results show that a large part of the wage gap cannot be explained by available characteristics and, indeed, in several countries the unexplained gap is larger than the total, suggesting that female characteristics are superior to the male ones. Though EUSILC does not have a public/private sector indicator, female employees in Public Administration and Defence have a lower disadvantage (than in the economy generally) in eight countries and a higher one in ten countries; for most countries, no 
significant effects can be discerned. The wage gap is wider when non-random selection into work is taken into account; this suggests that women in the selected samples are more highly qualified than in the population at large. When the decomposition is performed across the wage distribution using quantile regression, the unexplained gender wage gap widens at the top (glass ceiling effects) and at the bottom of the distribution (sticky floor effects) in many countries.

All our results suggest that gender wage gaps are larger when the restriction that individuals must be in full-time full-year employment is imposed. In Public Administration and Defence, nine rather than eight countries now have a lower gender disadvantage but the same number (ten) have a higher disadvantage than in the private sector. Thus the evidence that the public sector so defined is a progressive force where 'better' jobs are concerned is rather slight. In this alternative FTFY sample, glass ceiling effects are much more evident, with the number of countries displaying such behaviour doubling relative to the unconstrained sample. There is little difference between the two samples where sticky floor effects are concerned.

The size of the unexplained gender wage gap and the tremendous variation there exists across countries is a puzzle with tremendous policy dimensions, particularly in a political union where similar values are being promoted. It is, therefore, important to investigate the role that country-specific institutions and policies may have on the unexplained gender wage gap distributions. This exploration is not possible in individual-country studies or in studies which rely on a small number of observations. The 26 European countries in the EU SILC data protocol espouse, at least nominally, similar non-discriminatory attitudes but have different work-family reconciliation and labour market policies. It is then possible to examine whether taking these policies into account can help us understand the size of unexplained gender wage gap.

We find that generous policies concerning the reconciliation of work and family life reduce the mean and median unexplained wage gaps. These effects appear to also hold at the top end of the gender wage distribution but not at the bottom, where more generous work-family reconciliation policies may not only improve the welfare of existing female workers but may also encourage others to enter the labour force, moderating their wages. These effects hold for both the unconstrained sample and for 
the sample which is limited to full-time full-year workers, though in the latter our results are often sharper. The quantitative significance of the work-family reconciliation policies is substantial: In the working sample, a country with a low value of the work-family reconciliation index (I4) that adopts very progressive policies can improve the median of its gender wage gap distribution very substantially (by 0.185 ln wage points), taking it from the highest values of the country gender gap distribution to well-below the median. This effect is more limited at the $90^{\text {th }}$ percentile of country gender gap distributions but it is still of the order of a 0.065 ln wage point improvement. Generally similar comments hold for the FTFY sample.

Using the typology of countries (Largely Unregulated, Broadly Regulated and Highly Regulated) produced by the Hierarchical Cluster Analysis applied to a large array of wage-setting features in Du Caju et al. (2009), the effects of labour market institutions and policies are clearly defined when examined in isolation from family policies. Countries with largely unregulated labour markets have median and $90^{\text {th }}$ quantile wage gaps which are significantly higher than those in countries with some degree of regulation by approximately 0.080 ln wage points. This effect is more difficult to tease out when work-family reconciliation policies are controlled for at the same time. At the median, it appears that a largely unregulated country has a gender wage gap which is higher by 0.009 ln wage points but this effect is not significant. At the $90^{\text {th }}$ percentile, a highly regulated country has a gap which is lower by $0.066 \ln$ wage points, significant at the $1 \%$ level. Similar comments hold for the FTFY sample.

Among the various forms of work-family reconciliation policies, maternity benefits have the most uncertain effects. The Maternity variable carries a positive, typically not significant, coefficient, in contrast with the other work-family reconciliation variables which carry negative, significant, coefficients. Generous and long maternity support may encourage absences from the labour market which may make employers more reluctant to offer on-the-job training and more likely to hold back the career prospects of female employees; returning female workers may then earn lower wages. Thus, care should be taken in the design of work-family reconciliation policies.

Our findings suggest that the gender pay gap reflects the pattern of institutions and policies that prevail in each country. They also reduce the puzzle of why the 
unexplained component varies across countries and remains so high by appealing to cross-country differences in institutions and policies. Future work might also consider whether changes in institutions and policies may affect gender gaps over time.

\section{References}

Albrecht, J, Bjorklund, A, Vroman, S. Is there a glass ceiling in Sweden?. Journal of Labor Economics 2003; 21(1); 145-177.

Albrecht, J, van Vuuren, A, Vroman, S. Counterfactual distributions with sample selection adjustments: Econometric theory and an application to the Netherlands. Labour Economics 2009;16; 383-396.

Arulampalam, W, Booth, AL, Bryan, ML. Is there a glass ceiling over Europe? Exploring the gender pay gap across the wage distribution. Industrial and Labor Relations Review 2007;62(2); 163-186.

Beblo, M, Wolf, E. The wage penalties of heterogeneous employment biographies: An empirical analysis for Germany. Centre for European Economic Research (Discussion Paper No. 02-45); 2002, June.

Biewen, M, Jenkins, SP. A framework for the decomposition of poverty differences with an application to poverty differences between countries. Empirical Economics 2005;30; 331-358.

Blau, FD, Kahn, LM. The gender earnings gap: Learning from international comparisons. American Economic Review, American Economic Association 1992;82(2); 533-38, May.

Blau, FD, Kahn, LM. Wage structure and gender earnings differentials: An international comparison. Economica 1996;63(250); S29-S62.

Blau, FD, Kahn, LM. Understanding international differences in the gender pay gap. Journal of Labor Economics 2003;21(1); 106-144.

Booth, A.L, Francesconi, M. Union coverage and non-standard work in Britain. Oxford Economic Papers 2003;55(3); 383-416.

Brainerd, E. Women in transition: Changes in gender wage differentials in Eastern Europe and the former Soviet Union. Industrial and Labor Relations Review 2000;54(1); 138-162. 
Datta Gupta, N, Smith, N, Verner, M. The impact of Nordic countries’ family friendly policies on employment, wages, and children. Review of Economics of the Household 2008;6(1); 65-89.

de la Rica, S, Dolado, J, Llorens, V. Ceilings or floors? Gender wage gaps by education in Spain. Journal of Population Economics 2008;21(3); 751-776.

Del Boca, D, Vuri, D. The mismatch between employment and child care in Italy: The impact of rationing, Journal of Population Economics 2007;20(4); 805-832.

Eurostat. Reconciliation between work, private and family life in the European Union. Eurostat; 2009.

Du Caju, P, Gautier, E, Monferatou, D, Ward-Warmedinger, M. Institutional features of wage bargaining in 23 European countries, the US and Japan. Ekonomia 2009;12(2); 57-108.

Fortin, N, Lemieux, T, Firpo, S 2011. Decomposition methods in economics. In: Ashenfelter, O, Card, D (Eds.). Handbook of labor economics, Volume 4, Part A. Elsevier; 2011, Chapt. 1, 1-102.

Gosling, A, Machin, S, Meghir, C. The changing distribution of male wages in the U.K.. The Review of Economic Studies 2000;67(4); 635-666.

Gustafsson, S, Stafford, F. Child care subsidies and labor supply in Sweden. Journal of Human Resources 1992;27(1); 204-229.

Gutierrez-Domenech, M. Employment after motherhood: A European comparison. Labour Economics, 2005;12(1); 99-123.

Heckman, JJ. Shadow prices, market wages, and labour supply. Econometrica 1974;42(4); 679-94.

Heckman, JJ. Sample selection bias as a specification error. Econometrica 1979;47(1); 153-163.

Huber, M, Melly, B. Quantile regression in the presence of sample selection. unpublished manuscript; 2011.

Juhn, C, Murphy, KM, Pierce, B 1991. Accounting for the slowdown in black-white wage convergence. In: Kosters, MH (Ed), Workers and their wages. Washington DC: AEI Press; 1991, 107-143.

Kenjoh, E. New mothers' employment and public policy in the UK, Germany, the Netherlands, Sweden, and Japan. Labour 2005;19(sl); 5-49.

Koenker, R, Bassett, G. Regression quantiles. Econometrica 46(1), 33-50. 
Kunze, A. 2008, Gender wage gap studies: Consistency and decomposition. Empirical Economics 1978;35(1); 63-76.

Machado, JAF, Mata, J. Counterfactual decomposition of changes in wage distributions using quantile regression. Journal of Applied Econometrics 2005;20(4); 445-465.

Melly, B. Decomposition of differences in distribution using quantile regression. Labour Economics 2005;12(4); 577-590.

Nicodemo, C. Gender pay gap and quantile regression in European families. IZA Working Paper DP No.3978; 2009.

Ñopo, H. Matching as a tool to decompose wage gaps. Review of Economics and Statistics 2008;90(2); 290-299.

Oaxaca, RL, Ransom, MR. On discrimination and the decomposition of wage differentials. Journal of Econometrics 1994;61(1); 5-21.

OECD. Balancing work and family life: Helping parents into paid employment. Chapter 4 of Emloyment Outlook, Paris:OECD; 2001.

Olivetti, C, Petrongolo, B. Unequal pay or unequal employment? A cross country analysis of gender gaps. Journal of Labor Economics 2008;26(4); 621-654.

Plantenga, J, Remery, C (eds.). The gender pay gap - origins and policy responses. A comparative study of 30 European countries. European Commission, Directorate; 2006.

Ruhm, CJ. The economic consequences of parental leave mandates: Lessons from Europe. Quarterly Journal of Economics 1998;113(1); 285-317.

Sanchez-Mangas, R, Sanchez-Marcos, V. Balancing family and work; The effect of cash benefits for working mothers. Labour Economics 2008;15(6); 1127-1142.

Singh, SK, Maddala, GS. A function for size distribution of incomes. Econometrica 1976;44(5); 963-970.

Smith, MD. Modelling sample selection using Archimedean copulas. The Econometrics Journal 2003;6(1); 99-123.

Van Kerm, P. Generalised measures of wage differentials. Empirical Economics, forthcoming; 2012.

Viitanen, T. Costs of child care and female employment in England. Labour 2005;19; S149-S170. 
Waldfogel, J. The family gap for young women in the United States and Britain: Can maternity leave make a difference?. Journal of Labor Economics 1998;16(3); 505545.

Weichselbaumer, D, Winter-Ebmer, R. A meta-analysis of the international gender wage gap. Journal of Economic Surveys 2005;19; 479-511. 
Figure 1: The unconditional wage gap in European countries (working sample)

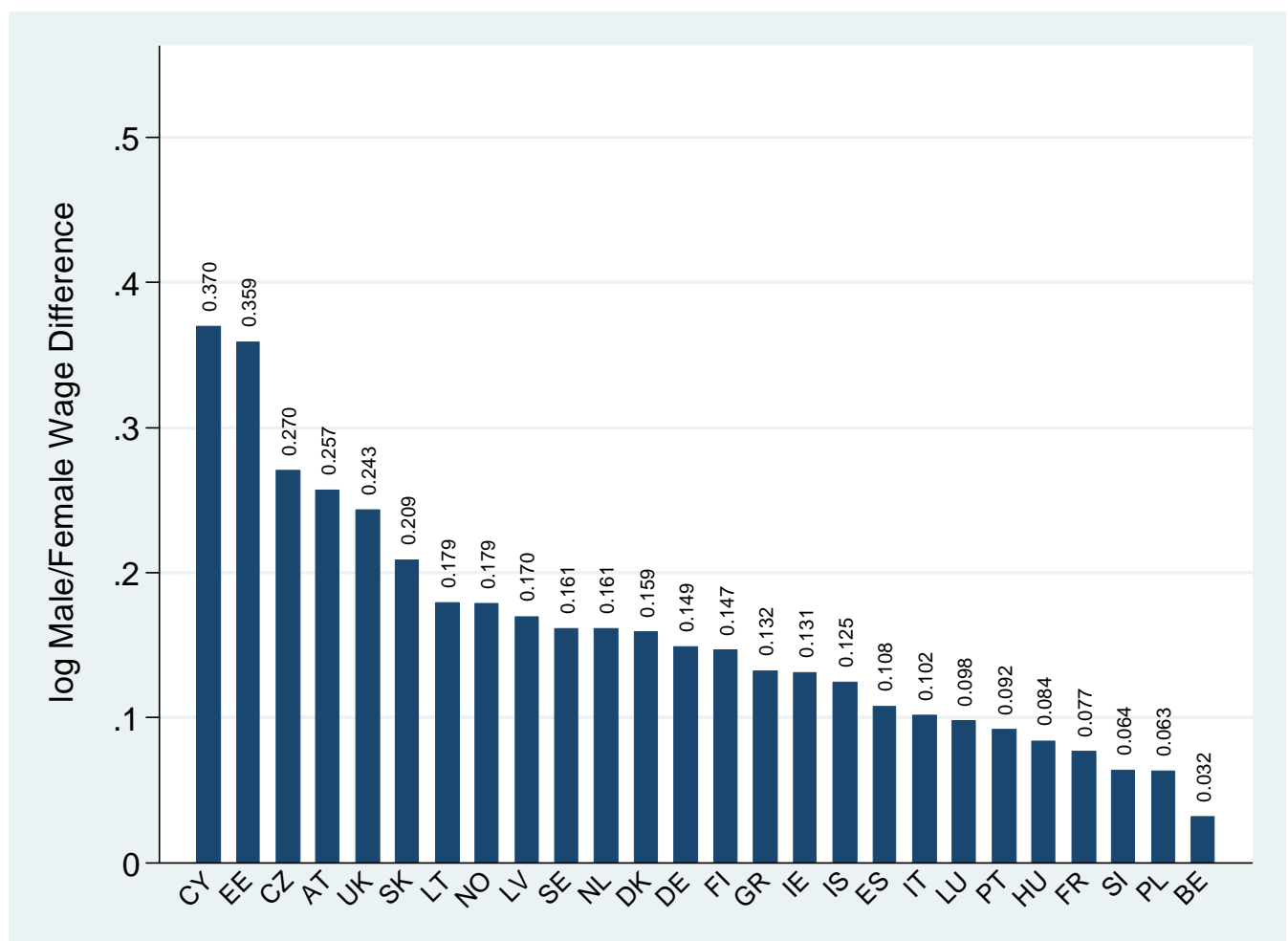

Note: $\mathrm{AT}=$ Austria, $\mathrm{BE}=$ Belgium, $\mathrm{CY}=$ Cyprus, $\mathrm{CZ}=$ Czech Republic, $\mathrm{DK}=$ Denmark, EE=Estonia, FI=Finland, FR=France, $\mathrm{DE}=$ Germany, $\mathrm{GR}=$ Greece, $\mathrm{HU}=$ Hungary, IS=Iceland, IE=Ireland, IT=Italy, LV=Latvia, LT=Lithuania, LU=Luxembourg, NO=Norway, NL=Netherlands, PL=Poland, PT=Portugal, SK=Slovak Republic, $\mathrm{SI}=$ Slovenia, ES=Spain, SE=Sweden, and UK=United Kingdom. 
Figure 2: Quantile regression decompositions (working sample)
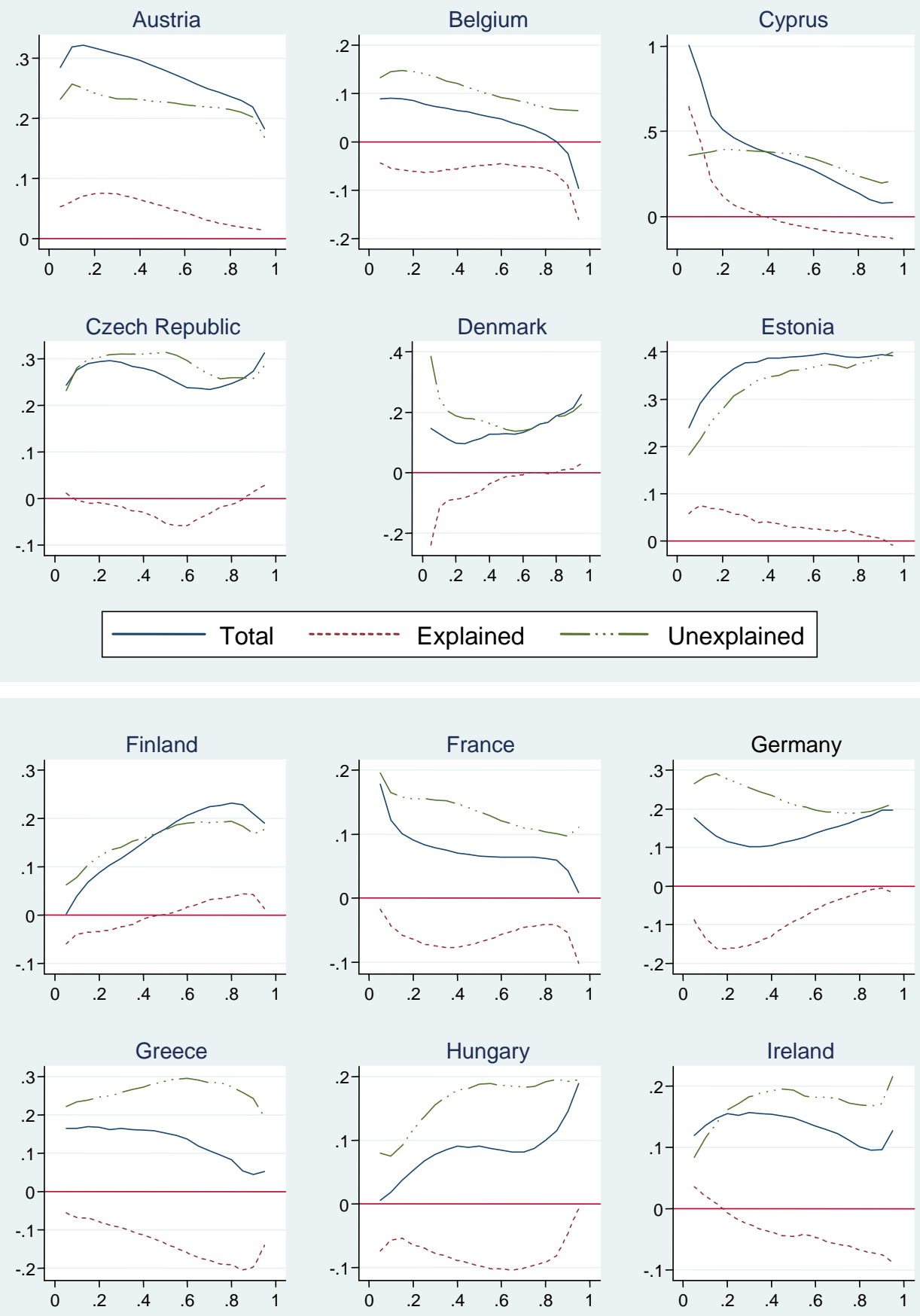

Total

Explained

\section{Unexplained}



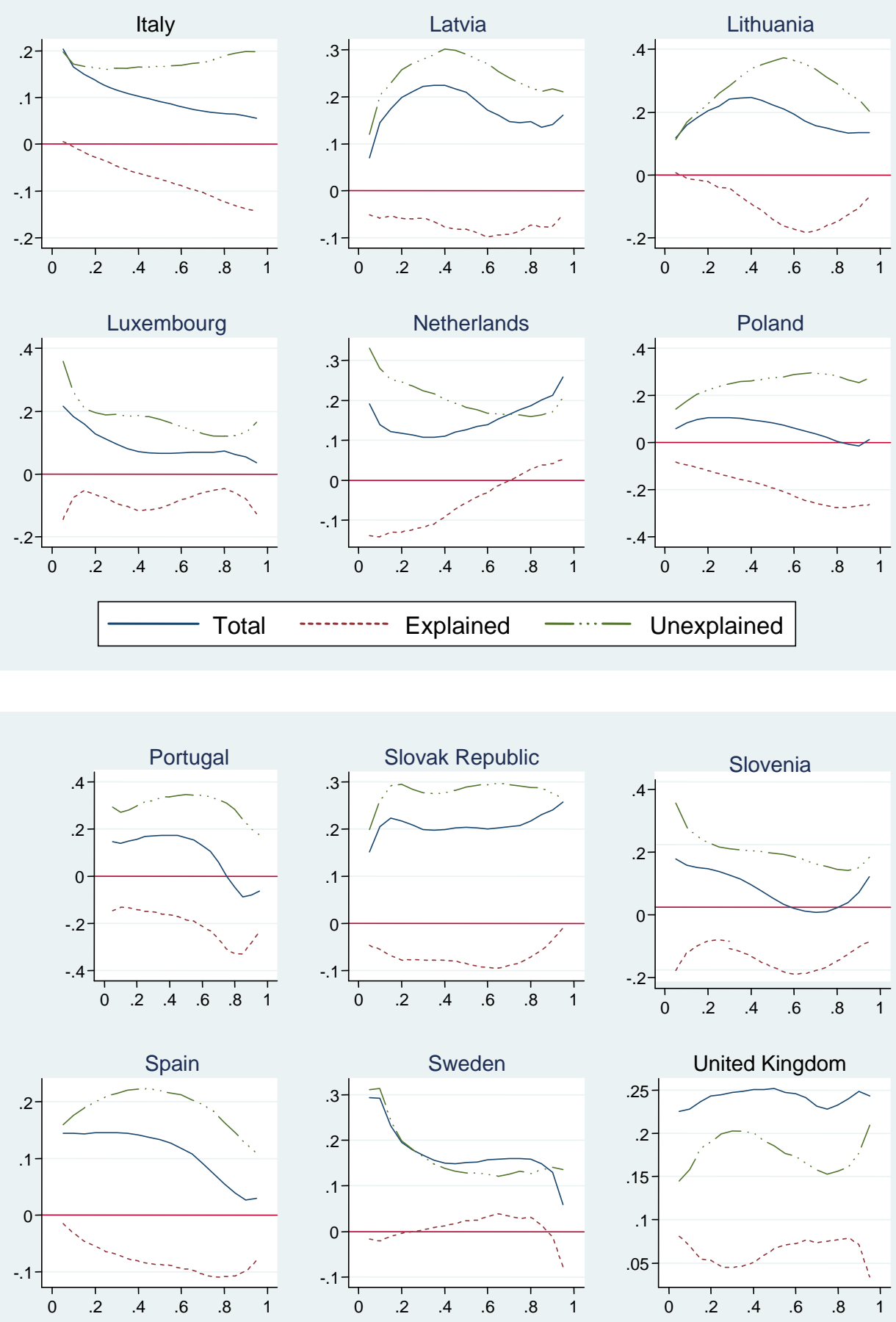

Total

Explained - - - Unexplained 


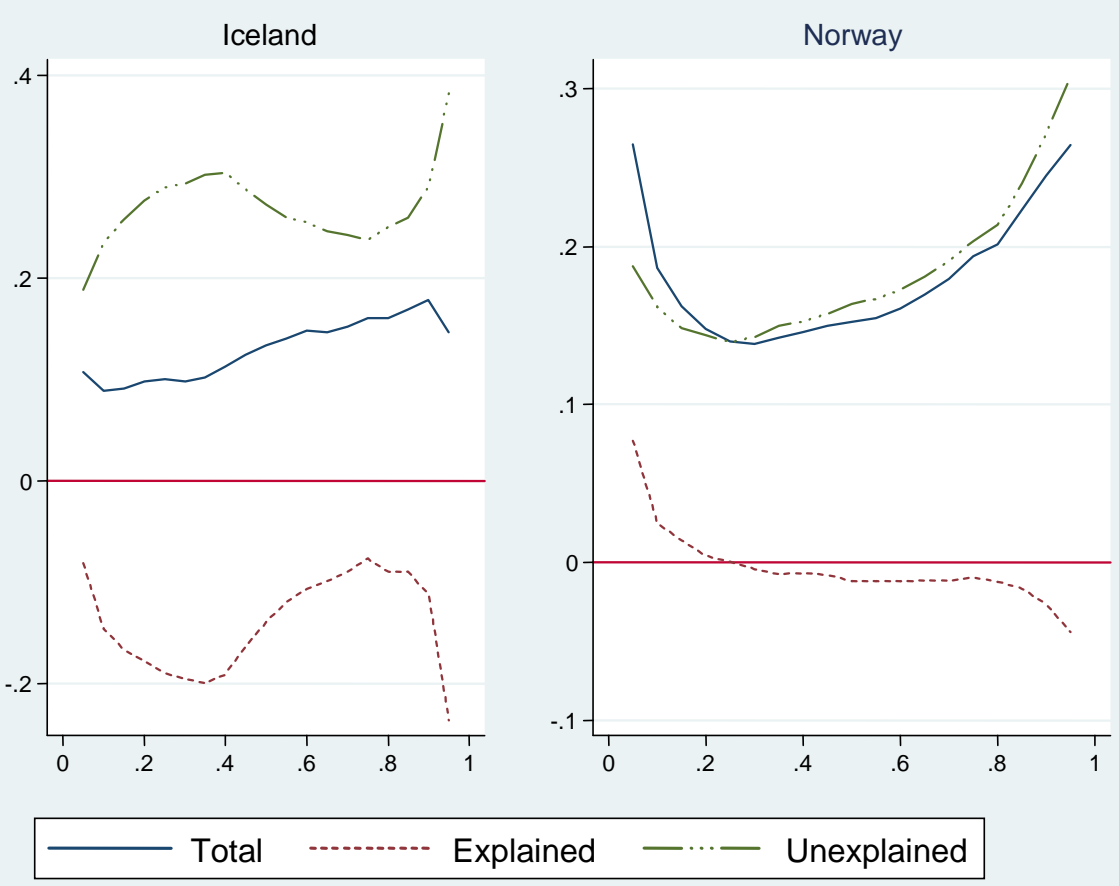


Figure 3: Simple regressions of features of unexplained gap on Composite Index (working sample)
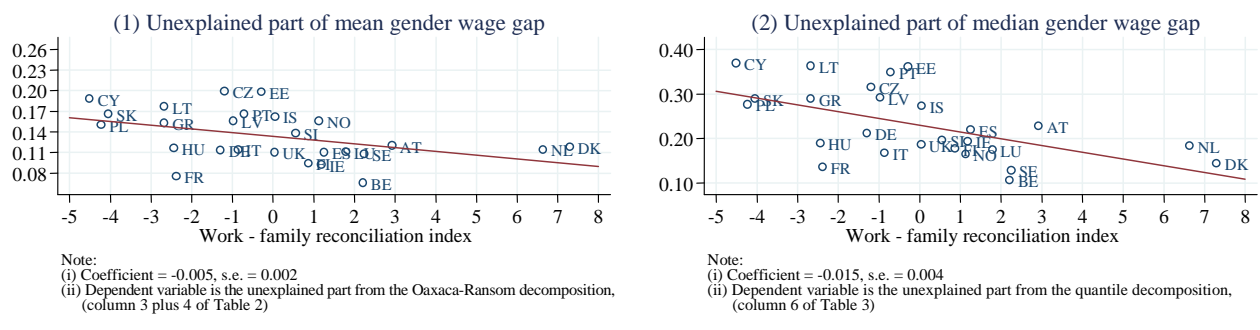

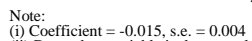

(ii) Dependent variable is the unexplained part from the quantile decomposition,
(column 6 of Table 3)

(3) Unexplained part of gender wage gap at the 90th quantile

(4) Unexplained part of gender wage gap at the 10th quantile

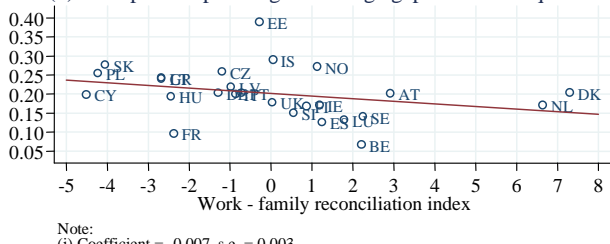

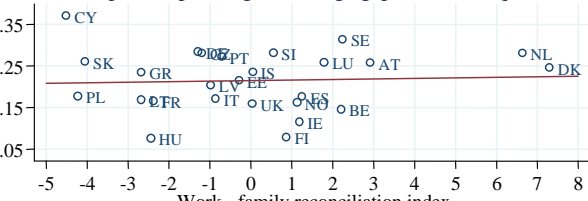

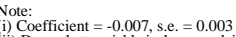

(ii) Dependent variable is the unexplained part of the decomposition at the 90th quantile
(column 10 of Table 3 )

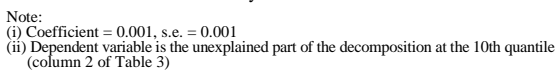


Table 1: Annual earnings, working hours and hourly wage rate by country (EU-SILC 2007)

\begin{tabular}{|c|c|c|c|c|c|c|c|c|c|c|c|c|}
\hline & \multicolumn{6}{|c|}{ Working sample } & \multicolumn{6}{|c|}{ FTFY sample } \\
\hline & \multicolumn{2}{|c|}{ Annual Earnings } & \multicolumn{2}{|c|}{ Working Hours } & \multicolumn{2}{|c|}{ Hourly Wage } & \multicolumn{2}{|c|}{ Annual Earnings } & \multicolumn{2}{|c|}{ Working Hours } & \multicolumn{2}{|c|}{ Hourly Wage } \\
\hline & Male & Female & Male & Female & Male & Female & Male & Female & Male & Female & Male & Female \\
\hline Austria & 35,361 & 21,774 & 41.62 & 31.78 & 16.89 & 13.43 & 37,115 & 29,129 & 42.30 & 40.63 & 17.03 & 13.90 \\
\hline Belgium & 37,422 & 30,975 & 41.00 & 37.71 & 18.63 & 19.44 & 38,506 & 33,750 & 41.61 & 39.96 & 17.89 & 16.32 \\
\hline Cyprus & 26,211 & 16,914 & 43.57 & 39.30 & 12.20 & 9.32 & 27,256 & 17,558 & 44.21 & 40.55 & 12.12 & 8.61 \\
\hline Czech Republic & 9,423 & 6,494 & 43.63 & 40.82 & 4.25 & 3.20 & 9,592 & 6,822 & 43.71 & 41.20 & 4.26 & 3.21 \\
\hline Denmark & 56,517 & 42,931 & 40.21 & 37.51 & 27.86 & 22.94 & 57,115 & 45,143 & 40.30 & 38.76 & 27.20 & 22.53 \\
\hline Estonia & 8,733 & 5,509 & 41.57 & 39.98 & 4.19 & 3.07 & 8,961 & 5,802 & 41.83 & 40.57 & 4.15 & 2.78 \\
\hline Finland & 38,320 & 28,430 & 40.51 & 38.12 & 19.29 & 16.75 & 40,967 & 31,153 & 41.09 & 39.24 & 19.31 & 15.33 \\
\hline France & 29,483 & 23,572 & 40.66 & 37.38 & 14.75 & 14.23 & 30,429 & 24,925 & 41.18 & 38.73 & 14.23 & 12.49 \\
\hline Germany & 40,043 & 31,092 & 43.96 & 40.91 & 18.07 & 15.67 & 41,512 & 33,200 & 44.14 & 42.11 & 18.27 & 15.30 \\
\hline Greece & 21,828 & 16,637 & 40.97 & 36.88 & 11.57 & 9.82 & 23,514 & 18,899 & 42.14 & 41.69 & 10.87 & 8.87 \\
\hline Hungary & 6,767 & 5,716 & 41.49 & 39.66 & 3.23 & 2.90 & 7,148 & 6,195 & 41.90 & 40.79 & 3.33 & 2.94 \\
\hline Iceland & 59,026 & 36,344 & 49.39 & 39.13 & 25.03 & 22.43 & 62,866 & 43,863 & 50.68 & 43.83 & 24.18 & 19.37 \\
\hline Ireland & 48,055 & 29,663 & 40.10 & 29.89 & 23.90 & 21.13 & 52,467 & 39,853 & 42.11 & 39.52 & 23.95 & 19.52 \\
\hline Italy & 27,153 & 20,231 & 40.77 & 34.07 & 13.26 & 12.33 & 28,516 & 23,892 & 41.90 & 39.59 & 13.28 & 11.80 \\
\hline Latvia & 7,024 & 5,397 & 43.80 & 40.91 & 3.19 & 2.67 & 7,193 & 5,505 & 43.98 & 41.55 & 3.19 & 2.59 \\
\hline Lithuania & 6,926 & 5,515 & 40.90 & 39.23 & 3.42 & 2.91 & 7,210 & 5,765 & 41.36 & 40.28 & 3.39 & 2.78 \\
\hline Luxembourg & 50,026 & 40,676 & 43.03 & 40.73 & 24.24 & 22.01 & 51,527 & 43,051 & 43.49 & 42.40 & 22.85 & 19.63 \\
\hline Netherlands & 44,412 & 35,805 & 38.95 & 37.40 & 23.47 & 19.34 & 45,098 & 36,949 & 39.22 & 37.72 & 22.34 & 19.02 \\
\hline Norway & 53,945 & 39,188 & 41.31 & 38.06 & 26.14 & 21.87 & 55,143 & 41,877 & 41.86 & 39.45 & 25.51 & 20.55 \\
\hline Poland & 7,411 & 6,060 & 42.83 & 38.20 & 3.54 & 3.37 & 7,924 & 6,474 & 43.64 & 41.39 & 3.56 & 3.05 \\
\hline Portugal & 14,696 & 13,053 & 41.47 & 37.91 & 7.03 & 7.54 & 15,204 & 14,157 & 41.73 & 39.37 & 7.19 & 7.16 \\
\hline Slovak Republic & 6,143 & 4,642 & 42.51 & 40.43 & 2.87 & 2.30 & 6,291 & 4,787 & 42.53 & 40.69 & 2.88 & 2.29 \\
\hline Slovenia & 16,824 & 15,408 & 41.88 & 40.56 & 8.12 & 7.64 & 17,370 & 16,173 & 42.25 & 41.20 & 8.02 & 7.64 \\
\hline Spain & 21,566 & 16,402 & 42.10 & 36.21 & 10.44 & 9.58 & 22,544 & 19,411 & 42.91 & 40.40 & 10.36 & 9.50 \\
\hline Sweden & 34,156 & 26,765 & 40.63 & 39.59 & 17.38 & 15.40 & 35,195 & 28,439 & 41.17 & 40.38 & 16.45 & 13.62 \\
\hline United Kingdom & 49,559 & 29,248 & 43.99 & 33.61 & 23.56 & 18.25 & 50,937 & 38,233 & 45.02 & 41.75 & 21.85 & 17.67 \\
\hline
\end{tabular}


Table 2: Oaxaca and Ransom (1994) decompositions (working sample)

\begin{tabular}{|c|c|c|c|c|c|c|c|c|}
\hline & \multicolumn{4}{|c|}{ Oaxaca-Ransom decomposition } & \multicolumn{4}{|c|}{ Heckman-corrected Oaxaca-Ransom decomposition } \\
\hline & \multirow[b]{2}{*}{ Total } & \multirow{2}{*}{$\begin{array}{c}\text { Explained } \\
\text { Endowments }\end{array}$} & \multicolumn{2}{|c|}{ Unexplained } & \multirow[b]{2}{*}{ Total } & \multirow{2}{*}{$\begin{array}{c}\text { Explained } \\
\text { Endowments }\end{array}$} & \multicolumn{2}{|c|}{ Unexplained } \\
\hline & & & $\begin{array}{c}\text { Male } \\
\text { Advantage }\end{array}$ & $\begin{array}{c}\text { Female } \\
\text { Disadvantage }\end{array}$ & & & $\begin{array}{c}\text { Male } \\
\text { Advantage }\end{array}$ & $\begin{array}{c}\text { Female } \\
\text { Disadvantage }\end{array}$ \\
\hline & $(1)$ & $(2)$ & (3) & $(4)$ & $(5)$ & $(6)$ & $(7)$ & $(8)$ \\
\hline Austria & $0.257 * * *$ & $0.137 * * *$ & $0.056^{* * *}$ & $0.064 * * *$ & $0.359 * * *$ & $0.082 * * *$ & $0.105^{* * *}$ & $0.172 * * *$ \\
\hline Belgium & $0.032 *$ & $-0.034 * * *$ & $0.024 * * *$ & $0.042 * * *$ & 0.041 & $-0.045 * * *$ & $0.052 * * *$ & 0.034 \\
\hline Cyprus & $0.370^{* * *}$ & $0.181^{* * *}$ & $0.088^{* * *}$ & $0.100^{* * *}$ & $0.375^{* * *}$ & $0.151^{* * *}$ & -0.022 & $0.247 * * *$ \\
\hline Czech Republic & $0.270 * * *$ & $0.072 * * *$ & $0.093 * * *$ & $0.106 * * *$ & $0.221 * * *$ & $0.044 * * *$ & -0.020 & $0.197 * * *$ \\
\hline Denmark & $0.159 * * *$ & $0.041^{*}$ & $0.055^{* * *}$ & $0.063 * * *$ & $0.145^{* * *}$ & 0.008 & $0.030 *$ & $0.107 * * *$ \\
\hline Estonia & $0.359 * * *$ & $0.161 * * *$ & $0.102^{* * *}$ & $0.096 * * *$ & $0.451 * * *$ & $0.141 * * *$ & $0.086 * * *$ & $0.224^{* * *}$ \\
\hline Finland & $0.147 * * *$ & $0.054 * * *$ & $0.046 * * *$ & $0.048 * * *$ & $0.131^{* * *}$ & $0.035 * * *$ & $0.037 * *$ & $0.059 * * *$ \\
\hline France & $0.077 * * *$ & 0.001 & $0.031 * * *$ & $0.044^{* * *}$ & $0.084^{* * *}$ & $-0.018 *$ & $0.031 * *$ & $0.071^{* * *}$ \\
\hline Germany & $0.149 * * *$ & $0.036 * * *$ & $0.038 * * *$ & $0.075 * * *$ & $0.174 * * *$ & 0.000 & $0.047 * * *$ & $0.127 * * *$ \\
\hline Greece & $0.132 * * *$ & -0.020 & $0.066^{* * *}$ & $0.087 * * *$ & $0.242 * * *$ & $-0.048 * * *$ & 0.033 & $0.257 * * *$ \\
\hline Hungary & $0.084^{* * *}$ & $-0.031^{* * *}$ & $0.057 * * *$ & $0.059 * * *$ & 0.000 & $-0.039 * * *$ & $-0.082 * * *$ & $0.121^{* * *}$ \\
\hline Iceland & $0.125^{* * *}$ & -0.037 & $0.080 * * *$ & $0.082 * * *$ & $0.153 * *$ & $-0.084 * * *$ & $0.072 * *$ & $0.165 * * *$ \\
\hline Ireland & $0.131^{* * *}$ & $0.040 * *$ & $0.048 * * *$ & $0.044 * * *$ & $0.184^{* * *}$ & 0.010 & $0.064 * *$ & $0.110 * * *$ \\
\hline Italy & $0.102^{* * *}$ & $-0.012 *$ & $0.051^{* * *}$ & $0.063 * * *$ & $0.123 * * *$ & $-0.035 * * *$ & $0.053 * * *$ & $0.105^{* * *}$ \\
\hline Luxembourg & $0.098 * * *$ & -0.012 & $0.037 * * *$ & $0.074 * * *$ & $0.156 * * *$ & $-0.039 *$ & $0.102 * * *$ & $0.093 * * *$ \\
\hline Netherlands & $0.161^{* * *}$ & $0.047 * * *$ & $0.025 * * *$ & $0.089 * * *$ & $0.234 * * *$ & $0.029 *$ & $0.064 * * *$ & $0.141^{* * *}$ \\
\hline Norway & $0.179 * * *$ & 0.023 & $0.062^{* * *}$ & $0.094 * * *$ & $0.203^{* * *}$ & 0.005 & $0.077 * * *$ & $0.121^{* * *}$ \\
\hline Poland & $0.063^{* * *}$ & $-0.087 * * *$ & $0.072 * * *$ & $0.078 * * *$ & 0.017 & $-0.101 * * *$ & $-0.153 * * *$ & $0.271 * * *$ \\
\hline Portugal & $0.092 * * *$ & $-0.074 * * *$ & $0.081^{* * *}$ & $0.085^{* * *}$ & 0.104 & $-0.112^{* * *}$ & -0.008 & $0.224^{* * *}$ \\
\hline Slovak Republic & $0.209 * * *$ & $0.043^{* * *}$ & $0.084^{* * *}$ & $0.082^{* * *}$ & $0.210 * * *$ & $0.037 * * *$ & $-0.059 * * *$ & $0.232 * * *$ \\
\hline Slovenia & $0.064 * * *$ & $-0.074 * * *$ & $0.072 * * *$ & $0.066 * * *$ & -0.033 & $-0.113 * * *$ & -0.022 & $0.102 * * *$ \\
\hline Spain & $0.108^{* * *}$ & -0.002 & $0.050 * * *$ & $0.060 * * *$ & $0.186 * * *$ & $-0.030 * * *$ & $0.056^{*}$ & $0.160 * * *$ \\
\hline Sweden & $0.161^{* * *}$ & $0.054 * * *$ & $0.046 * * *$ & $0.062 * * *$ & $0.202 * * *$ & 0.017 & $0.050 * *$ & $0.135 * * *$ \\
\hline United Kingdom & $0.243 * * *$ & $0.134 * * *$ & $0.058 * * *$ & $0.052 * * *$ & $0.236^{* * *}$ & $0.113^{* * *}$ & 0.026 & $0.097 * * *$ \\
\hline European Union & $0.246 * * *$ & $-0.082 * * *$ & $0.149 * * *$ & $0.179 * * *$ & $0.933^{* * *}$ & $-0.170 * * *$ & $0.648 * * *$ & $0.455^{* * *}$ \\
\hline
\end{tabular}
equation (1)) measures the part of the predicted average wage difference that can be explained by the difference between the male and female characteristics. The unexplained part (the second and third terms of equation (1)) corresponds to the male advantage and female disadvantage. Three stars indicate significance at the $1 \%$, two stars at the $5 \%$ and one star at the $10 \%$ level. 
Table 2a: The contribution of the public sector to the Oaxaca and Ransom (1994) decompositions (working sample)

\begin{tabular}{|c|c|c|c|c|c|c|c|c|c|}
\hline & \multirow[b]{2}{*}{ Total } & \multirow[b]{2}{*}{ Endowments } & \multirow[b]{2}{*}{$\begin{array}{c}\text { Male } \\
\text { Advantage }\end{array}$} & \multirow[b]{2}{*}{$\begin{array}{c}\text { Female } \\
\text { Disadvantage }\end{array}$} & \multicolumn{3}{|c|}{ Effect of public on decomposition } & \multicolumn{2}{|c|}{$\begin{array}{l}\text { Effect of public on } \\
\text { wage estimation }\end{array}$} \\
\hline & & & & & Endowments & $\begin{array}{c}\text { Male } \\
\text { Advantage }\end{array}$ & $\begin{array}{c}\text { Female } \\
\text { Disadvantage }\end{array}$ & Male & Female \\
\hline Austria & $0.257 * * *$ & $0.137 * * *$ & $0.056^{* * *}$ & $0.064 * * *$ & 0.001 & -0.002 & 0.000 & 0.015 & 0.038 \\
\hline Belgium & $0.032 *$ & $-0.034 * * *$ & $0.024 * * *$ & $0.042 * * *$ & -0.000 & -0.003 & -0.006 & $-0.039 *$ & 0.029 \\
\hline Cyprus & $0.370 * * *$ & $0.181 * * *$ & $0.088 * * *$ & $0.100 * * *$ & $0.005^{* * *}$ & -0.002 & 0.002 & $0.136 * * *$ & $0.132 * * *$ \\
\hline Czech Republic & $0.270 * * *$ & $0.072 * * *$ & $0.093 * * *$ & $0.106^{* * *}$ & -0.001 & $-0.003^{*}$ & 0.001 & $0.069 * * *$ & $0.086 * * *$ \\
\hline Denmark & $0.159 * * *$ & $0.041 *$ & $0.055^{* * *}$ & $0.063 * * *$ & 0.000 & -0.001 & -0.001 & -0.031 & -0.005 \\
\hline Estonia & $0.359 * * *$ & $0.161 * * *$ & $0.102^{* * *}$ & $0.096 * * *$ & -0.000 & -0.002 & 0.001 & -0.026 & -0.015 \\
\hline Finland & $0.147 * * *$ & $0.054 * * *$ & $0.046 * * *$ & $0.048 * * *$ & -0.000 & 0.003 & $0.004 *$ & 0.056 & -0.029 \\
\hline France & $0.077 * * *$ & 0.001 & $0.031^{* * *}$ & $0.044 * * *$ & -0.001 & 0.001 & 0.002 & 0.030 & 0.010 \\
\hline Germany & $0.149 * * *$ & $0.036 * * *$ & $0.038 * * *$ & $0.075 * * *$ & $-0.006 * * *$ & 0.000 & -0.001 & $0.110 * * *$ & $0.115^{* * *}$ \\
\hline Greece & $0.132 * * *$ & -0.020 & $0.066^{* * *}$ & $0.087 * * *$ & $0.005^{* *}$ & -0.004 & -0.001 & $0.108 * * *$ & $0.144 * * *$ \\
\hline Hungary & $0.084^{* * *}$ & $-0.031^{* * *}$ & $0.057 * * *$ & $0.059 * * *$ & -0.001 & 0.002 & 0.002 & $0.114^{* * *}$ & $0.077 * * *$ \\
\hline Ireland & $0.131^{* * *}$ & $0.040 * *$ & $0.048 * * *$ & $0.044 * * *$ & $-0.004 * *$ & 0.002 & 0.006 & $0.174 * * *$ & $0.112 * * *$ \\
\hline Iceland & $0.125 * * *$ & -0.037 & $0.080^{* * *}$ & $0.082 * * *$ & -0.002 & 0.003 & 0.001 & $0.151^{*}$ & 0.095 \\
\hline Italy & $0.102 * * *$ & $-0.012 *$ & $0.051 * * *$ & $0.063 * * *$ & $0.002 * * *$ & 0.001 & 0.001 & $0.094 * * *$ & $0.075^{* * *}$ \\
\hline Latvia & $0.170 * * *$ & 0.014 & $0.080 * * *$ & $0.076 * * *$ & -0.001 & $-0.011 * * *$ & $-0.007 * *$ & -0.037 & $0.153 * * *$ \\
\hline Lithuania & $0.179 * * *$ & 0.003 & $0.089 * * *$ & $0.088 * * *$ & 0.001 & $-0.006 * *$ & -0.001 & 0.044 & $0.130 * * *$ \\
\hline Luxembourg & $0.098 * * *$ & -0.012 & $0.037 * * *$ & $0.074 * * *$ & $0.006^{* * *}$ & 0.000 & 0.004 & $0.205 * * *$ & $0.139 * *$ \\
\hline Norway & $0.179 * * *$ & 0.023 & $0.062 * * *$ & $0.094 * * *$ & 0.002 & 0.001 & -0.001 & -0.035 & -0.039 \\
\hline Netherlands & $0.161 * * *$ & $0.047 * * *$ & $0.025 * * *$ & $0.089 * * *$ & -0.002 & $-0.003^{*}$ & $-0.012 * *$ & $0.059 * *$ & $0.175 * * *$ \\
\hline Poland & $0.063^{* * *}$ & $-0.087 * * *$ & $0.072 * * *$ & $0.078 * * *$ & $-0.001 * *$ & 0.001 & 0.001 & $0.113^{* * *}$ & $0.087 * * *$ \\
\hline Portugal & $0.092 * * *$ & $-0.074 * * *$ & $0.081 * * *$ & $0.085 * * *$ & $0.005^{* * *}$ & -0.004 & $0.008 * *$ & $0.091^{* *}$ & 0.031 \\
\hline Slovak Republic & $0.209 * * *$ & $0.043^{* * *}$ & $0.084 * * *$ & $0.082 * * *$ & -0.001 & 0.002 & -0.003 & 0.029 & 0.027 \\
\hline Slovenia & $0.064 * * *$ & $-0.074 * * *$ & $0.072 * * *$ & $0.066^{* * *}$ & 0.001 & 0.000 & -0.000 & -0.074 & $-0.071^{*}$ \\
\hline Spain & $0.108 * * *$ & -0.002 & $0.050 * * *$ & $0.060 * * *$ & -0.001 & 0.000 & 0.001 & $0.148 * * *$ & $0.134 * * *$ \\
\hline Sweden & $0.161^{* * *}$ & $0.054 * * *$ & $0.046^{* * *}$ & $0.062 * * *$ & 0.001 & -0.000 & -0.003 & -0.053 & -0.010 \\
\hline United Kingdom & $0.243 * * *$ & $0.134 * * *$ & $0.058 * * *$ & $0.052 * * *$ & $-0.002 * *$ & -0.002 & -0.001 & $0.105^{* * *}$ & $0.136 * * *$ \\
\hline EU & $0.246 * * *$ & $-0.082 * * *$ & $0.149 * * *$ & $0.179 * * *$ & $-0.001 * * *$ & -0.001 & -0.000 & & \\
\hline
\end{tabular}


Table 3: Quantile regression decompositions (working sample)

\begin{tabular}{|c|c|c|c|c|c|c|c|c|c|c|c|c|}
\hline \multirow[b]{3}{*}{ Austria } & \multicolumn{10}{|c|}{ Quantile decompositions } & \multicolumn{2}{|c|}{$\begin{array}{l}\text { Oaxaca-Ransom } \\
\text { decompositions }\end{array}$} \\
\hline & \multicolumn{2}{|c|}{$10 \%$} & \multicolumn{2}{|c|}{$25 \%$} & \multicolumn{2}{|c|}{$50 \%$} & \multicolumn{2}{|c|}{$75 \%$} & \multicolumn{2}{|c|}{$90 \%$} & & \\
\hline & 0.319 & {$[0.257]$} & 0.312 & {$[0.237]$} & 0.281 & {$[0.227]$} & 0.243 & {$[0.217]$} & 0.219 & {$[0.202]$} & 0.257 & [0.120] \\
\hline Belgium & 0.091 & {$[0.146]$} & 0.079 & {$[0.142]$} & 0.057 & {$[0.105]$} & 0.025 & {$[0.077]$} & -0.024 & {$[0.066]$} & 0.032 & {$[0.066]$} \\
\hline Cyprus & 0.818 & {$[0.370]$} & 0.464 & [0.395] & 0.326 & {$[0.370]$} & 0.17 & {$[0.266]$} & 0.081 & [0.199] & 0.370 & [0.189] \\
\hline Czech Republic & 0.276 & {$[0.280]$} & 0.296 & {$[0.310]$} & 0.262 & [0.315] & 0.239 & {$[0.257]$} & 0.273 & {$[0.258]$} & 0.270 & [0.198] \\
\hline Denmark & 0.129 & {$[0.246]$} & 0.097 & {$[0.180]$} & 0.130 & {$[0.143]$} & 0.167 & [0.169] & 0.216 & {$[0.203]$} & 0.159 & {$[0.118]$} \\
\hline Estonia & 0.290 & [0.215] & 0.364 & {$[0.307]$} & 0.390 & {$[0.361]$} & 0.389 & {$[0.366]$} & 0.395 & [0.389] & 0.359 & {$[0.198]$} \\
\hline Finland & 0.039 & [0.079] & 0.104 & {$[0.134]$} & 0.179 & {$[0.177]$} & 0.228 & [0.193] & 0.210 & [0.168] & 0.147 & [0.093] \\
\hline France & 0.122 & [0.165] & 0.083 & [0.155] & 0.066 & [0.135] & 0.064 & [0.108] & 0.042 & [0.096] & 0.077 & {$[0.076]$} \\
\hline Germany & 0.151 & {$[0.284]$} & 0.108 & [0.267] & 0.119 & [0.211] & 0.163 & [0.189] & 0.197 & {$[0.202]$} & 0.149 & [0.113] \\
\hline Greece & 0.165 & {$[0.234]$} & 0.162 & {$[0.251]$} & 0.153 & [0.289] & 0.095 & [0.284] & 0.045 & {$[0.243]$} & 0.132 & {$[0.152]$} \\
\hline Hungary & 0.019 & [0.075] & 0.068 & [0.137] & 0.091 & [0.189] & 0.088 & [0.184] & 0.146 & [0.193] & 0.084 & [0.115] \\
\hline Iceland & 0.089 & {$[0.235]$} & 0.100 & [0.290] & 0.133 & [0.273] & 0.161 & [0.238] & 0.178 & [0.290] & 0.125 & {$[0.162]$} \\
\hline Ireland & 0.136 & [0.115] & 0.152 & {$[0.170]$} & 0.147 & [0.193] & 0.111 & {$[0.172]$} & 0.096 & {$[0.171]$} & 0.131 & {$[0.091]$} \\
\hline Italy & 0.166 & {$[0.171]$} & 0.125 & [0.161] & 0.092 & [0.166] & 0.068 & {$[0.181]$} & 0.060 & [0.199] & 0.102 & {$[0.114]$} \\
\hline Latvia & 0.146 & [0.203] & 0.211 & [0.271] & 0.210 & [0.291] & 0.144 & {$[0.230]$} & 0.141 & [0.218] & 0.170 & {$[0.156]$} \\
\hline Lithuania & 0.159 & [0.168] & 0.220 & {$[0.260]$} & 0.222 & [0.363] & 0.150 & [0.311] & 0.135 & {$[0.240]$} & 0.179 & {$[0.176]$} \\
\hline Luxembourg & 0.183 & [0.259] & 0.111 & [0.188] & 0.065 & {$[0.174]$} & 0.070 & [0.121] & 0.054 & {$[0.132]$} & 0.098 & {$[0.110]$} \\
\hline Netherlands & 0.139 & {$[0.280]$} & 0.113 & {$[0.236]$} & 0.127 & [0.183] & 0.177 & [0.164] & 0.212 & {$[0.170]$} & 0.161 & {$[0.114]$} \\
\hline Norway & 0.186 & {$[0.162]$} & 0.140 & [0.139] & 0.152 & [0.164] & 0.194 & {$[0.203]$} & 0.245 & {$[0.272]$} & 0.179 & {$[0.156]$} \\
\hline Poland & 0.083 & [0.177] & 0.105 & [0.237] & 0.083 & {$[0.276]$} & 0.022 & [0.291] & -0.014 & {$[0.255]$} & 0.063 & {$[0.150]$} \\
\hline Portugal & 0.140 & {$[0.272]$} & 0.169 & [0.317] & 0.164 & [0.348] & 0.001 & [0.311] & -0.080 & [0.203] & 0.092 & {$[0.166]$} \\
\hline Slovak Republic & 0.205 & [0.260] & 0.209 & [0.285] & 0.204 & [0.289] & 0.208 & [0.292] & 0.240 & {$[0.276]$} & 0.209 & {$[0.166]$} \\
\hline Slovenia & 0.135 & {$[0.281]$} & 0.113 & {$[0.217]$} & 0.029 & {$[0.196]$} & -0.014 & [0.155] & 0.047 & {$[0.150]$} & 0.064 & {$[0.138]$} \\
\hline Spain & 0.145 & {$[0.176]$} & 0.145 & [0.209] & 0.133 & [0.219] & 0.074 & [0.183] & 0.027 & {$[0.125]$} & 0.108 & {$[0.110]$} \\
\hline Sweden & 0.292 & [0.313] & 0.179 & [0.179] & 0.151 & [0.128] & 0.160 & [0.132] & 0.130 & {$[0.140]$} & 0.161 & {$[0.107]$} \\
\hline United Kingdom & 0.228 & {$[0.158]$} & 0.245 & [0.199] & 0.252 & [0.185] & 0.228 & {$[0.153]$} & 0.249 & [0.178] & 0.243 & {$[0.109]$} \\
\hline
\end{tabular}

Note: The decomposition methodology is described in section 4.2. The decompositions are estimated at the 10th, 25th, 50th, 75th and 90th quantile. For each of the reported quantiles, the difference between the actual ln-earnings for the two genders is reported first, followed by the portion which is not explained by the quantile regressions in square brackets. The last two columns provide the (no selection) total and unexplained wage gaps from Table 2 . The male advantage and female disadvantage are summed up to produce the unexplained part of the Oaxaca-Ransom decomposition. 
Table 4: Quantile evidence on sticky floors and glass ceilings (working sample)

\begin{tabular}{|c|c|c|c|c|c|c|c|}
\hline & \multicolumn{3}{|c|}{ Sticky floor measured by ${ }^{\mathrm{a}}$ : } & \multicolumn{3}{|c|}{ Glass ceiling measured by ${ }^{\mathrm{b}}$ : } & \multirow[b]{2}{*}{$\begin{array}{l}\text { Shape of } \\
\text { total actual } \\
\text { earnings } \\
\text { distribution }\end{array}$} \\
\hline & $\begin{array}{c}\begin{array}{c}10- \\
\text { all } \\
\text { Gaps }\end{array} \\
(1)\end{array}$ & $\begin{array}{c}\begin{array}{c}10-25 \\
\text { Difference }\end{array} \\
(2)\end{array}$ & $\begin{array}{c}\begin{array}{c}10-50 \\
\text { Difference }\end{array} \\
(3)\end{array}$ & $\begin{array}{c}90- \\
\text { all } \\
\text { Gaps }\end{array}$ & $\begin{array}{c}\begin{array}{c}90-75 \\
\text { Difference }\end{array} \\
(5)\end{array}$ & $\begin{array}{c}\begin{array}{c}90-50 \\
\text { Difference }\end{array} \\
(6)\end{array}$ & \\
\hline Austria & & & Yes & & & & Inverse U \\
\hline Belgium & & & Yes & & & & Decreasing \\
\hline Cyprus & Yes & Yes* & Yes* & & & & Decreasing \\
\hline Czech Republic & & & & & Yes & & Complex \\
\hline Denmark & & Yes & & Yes & Yes & Yes & U-Shaped \\
\hline Estonia & & & & & & & Increasing \\
\hline Finland & & & & & & Yes & Inverse U \\
\hline France & Yes & Yes* & Yes* & & & & Decreasing \\
\hline Germany & & Yes & Yes & Yes & Yes & Yes* & U-Shaped \\
\hline Greece & & & & & & & Decreasing \\
\hline Hungary & & & & Yes & Yes & Yes & Complex \\
\hline Iceland & & & & & & Yes & Complex \\
\hline Ireland & & & & & & & Complex \\
\hline Italy & Yes & Yes* & Yes* & & & & Decreasing \\
\hline Latvia & & & & & & & Complex \\
\hline Lithuania & & & & & & & Inverse U \\
\hline Luxembourg & Yes & Yes* & Yes* & & & & Decreasing \\
\hline Netherlands & & Yes & & Yes & Yes & Yes* & U-Shaped \\
\hline Norway & & Yes & Yes & Yes & Yes & Yes* & U-Shaped \\
\hline Poland & & & & & & & Complex \\
\hline Portugal & & & & & & & Complex \\
\hline Slovak Republic & & & & Yes & Yes & Yes & Complex \\
\hline Slovenia & Yes & Yes & Yes* & & Yes & & U-Shaped \\
\hline Spain & & & & & & & Decreasing \\
\hline Sweden & Yes & Yes* & Yes* & & & & Complex \\
\hline United Kingdom & & & & & Yes & & Complex \\
\hline
\end{tabular}

Notes: ${ }^{\text {a }} \mathrm{A}$ 'glass ceiling' effect is defined to exist if the $90^{\text {th }}$ percentile wage gap exceeds the reference gap by at least two percentage points. ${ }^{\mathrm{b}} \mathrm{A}$ 'sticky floor' effect is defined to exist if the $10^{\text {th }}$ percentile wage gap exceeds the reference gap by at least two percentage points. A * indicates (i) glass ceiling effects where the $90^{\text {th }}$ percentile minus 1.96 times the standard error (i.e. a low upper bound) exceeds the reference gap plus 1.96 times the standard error (i.e. a high lower bound) or (ii) sticky floor effects where the $10^{\text {th }}$ percentile minus 1.96 times the standard error (i.e. a low lower bound) exceeds the reference gap plus 1.96 times the standard error (i.e. a high upper bound). These would be extreme forms of the effects and they are,, naturally, more rare. Consistent with earlier literature, these descriptive effects derive from the total quantiles. 
Table 5: Indicators of work-family policies and wage-setting institutions

\begin{tabular}{|c|c|c|c|c|c|c|c|c|}
\hline & $\begin{array}{c}\text { Formal } \\
\text { Child- } \\
\text { care } \\
\text { coverage } \\
\text { for under } \\
\text { three }^{\S}\end{array}$ & $\begin{array}{c}\text { Maternity } \\
\text { pay } \\
\text { entitlement }^{\S}\end{array}$ & $\begin{array}{l}\text { Voluntary } \\
\text { part-time } \\
\text { working }^{\S}\end{array}$ & $\begin{array}{l}\text { Adjust } \\
\text { working } \\
\text { day for } \\
\text { family } \\
\text { reasons }^{\S}\end{array}$ & $\begin{array}{c}\text { Take } \\
\text { leave for } \\
\text { family } \\
\text { reasons }\end{array}$ & $\begin{array}{c}\text { Composite } \\
\text { Index }^{\dagger}\end{array}$ & $I 4^{\&}$ & 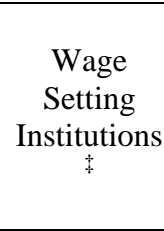 \\
\hline Austria & -1.09 & 0.21 & 1.49 & 0.85 & 1.47 & 2.93 & 2.72 & $\mathrm{BR}$ \\
\hline Belgium & 0.38 & -1.08 & 1.20 & 0.73 & 0.99 & 2.21 & 3.30 & HR \\
\hline Cyprus & -0.16 & -0.44 & -0.78 & -1.23 & -1.90 & -4.51 & -4.07 & HR \\
\hline Czech Republic & -1.09 & 1.17 & -0.78 & -0.44 & -0.06 & -1.19 & -2.37 & LU \\
\hline Denmark & 3.54 & 0.85 & -0.06 & 1.34 & 1.63 & 7.30 & 6.45 & $\mathrm{BR}$ \\
\hline Estonia & -0.39 & 1.49 & -0.56 & -0.68 & -0.14 & -0.28 & -1.77 & LU \\
\hline Finland & 0.38 & 0.21 & -0.77 & 1.03 & 0.02 & 0.87 & 0.66 & HR \\
\hline France & 0.15 & -1.08 & 0.14 & -0.56 & -1.02 & -2.37 & -1.29 & BR \\
\hline Germany & -0.47 & -0.44 & 1.20 & -1.05 & -0.54 & -1.29 & -0.86 & $\mathrm{BR}$ \\
\hline Greece & -0.78 & 0.21 & -0.90 & -0.74 & -0.46 & -2.67 & -2.88 & $\mathrm{BR}$ \\
\hline Hungary & -0.70 & 0.53 & -0.91 & -0.74 & -0.62 & -2.44 & -2.97 & LU \\
\hline Iceland $^{\#}$ & 1.23 & -1.72 & 0.55 & 0.00 & 0.00 & 0.05 & 1.78 & na \\
\hline Ireland $^{\#}$ & -0.62 & 1.81 & 0.00 & 0.00 & 0.00 & 1.19 & -0.62 & $\mathrm{BR}$ \\
\hline Italy & 0.15 & 0.53 & -0.01 & -0.74 & -0.78 & -0.86 & -1.38 & $\mathrm{BR}$ \\
\hline Latvia & 0.15 & 0.21 & -0.89 & -0.37 & -0.06 & -0.97 & -1.17 & na \\
\hline Lithuania & -0.39 & 0.85 & -0.69 & -1.41 & -1.02 & -2.67 & -3.51 & LU \\
\hline Luxembourg & -0.47 & 0.21 & 1.10 & 1.34 & -0.38 & 1.79 & 1.59 & HR \\
\hline Netherlands & -0.78 & 0.21 & 2.80 & 2.62 & 1.79 & 6.64 & 6.43 & $\mathrm{BR}$ \\
\hline Norway & 0.61 & -2.69 & 0.63 & 1.03 & 1.55 & 1.13 & 3.82 & $\mathrm{BR}$ \\
\hline Poland & -0.93 & 0.21 & -0.89 & -1.35 & -1.26 & -4.22 & -4.43 & LU \\
\hline Portugal & 0.92 & 0.53 & -0.92 & -0.37 & -0.86 & -0.71 & -1.23 & $\mathrm{BR}$ \\
\hline Slovak Republic & -0.85 & -0.12 & -0.91 & -0.99 & -1.18 & -4.04 & -3.93 & na \\
\hline Slovenia $^{\#}$ & 0.61 & 0.00 & -0.91 & 0.11 & 0.75 & 0.56 & 0.56 & HR \\
\hline Spain & -0.01 & 0.53 & -0.57 & 0.48 & 0.83 & 1.26 & 0.73 & HR \\
\hline Sweden & 1.31 & -1.08 & 0.27 & 0.60 & 1.15 & 2.25 & 3.33 & $\mathrm{BR}$ \\
\hline United Kingdom & -0.70 & -1.08 & 1.17 & 0.54 & 0.10 & 0.04 & 1.11 & LU \\
\hline
\end{tabular}

Sources: ${ }^{\S}$ Data for the first five columns are drawn from Eurostat (2009). ${ }^{\dagger}$ The composite index is the sum of the first five columns in the table. ${ }^{\ddagger} \mathrm{HR}$ stands for highly regulated, BR for broadly regulated, and LU for largely unregulated as in Du Caju et al (2009). Iceland, Latvia and the Slovak Republic are not available in the Du Caju et al (2009) study (na).

Notes: ${ }^{\S}$ All indicators in the first five columns are scaled in order to have a zero mean and standard deviation equal to unity. So, a value of zero implies that the country concerned is at the average value for the countries in the table. "Maternity pay entitlement is missing for Slovenia; Voluntary part-time working, Adjust working day for family reasons and Take leave for family reasons are missing for Ireland and the last two are missing for Iceland. Missing values are replaced with the mean value of the rest of the sample. ${ }^{\&}$ Column I4 is the sum of columns 1, 3, 4 and 5. 
Table 6: Dependent variable is the unexplained part of the Melly median wage gap (working sample)

\begin{tabular}{|c|c|c|c|c|c|c|c|c|c|c|}
\hline & $(1)$ & $(2)$ & $(3)$ & $(4)$ & $(5)$ & (6) & $(7)$ & $(8)$ & (9) & $(10)$ \\
\hline Child Care & $\begin{array}{c}-0.025^{* *} \\
(0.010)\end{array}$ & & & & & & & & & \\
\hline Maternity & & $\begin{array}{c}0.028 * \\
(0.015)\end{array}$ & & & & & $\begin{array}{c}0.015 \\
(0.013)\end{array}$ & & & $\begin{array}{c}0.021 \\
(0.013)\end{array}$ \\
\hline Vol. part-time & & & $\begin{array}{c}-0.041^{* * *} \\
(0.013)\end{array}$ & & & & & & & \\
\hline Adjust work day & & & & $\begin{array}{c}-0.048 * * * \\
(0.013)\end{array}$ & & & & & & \\
\hline Family days off & & & & & $\begin{array}{c}-0.044^{* * *} \\
(0.012)\end{array}$ & & & & & \\
\hline Composite index & & & & & & $\begin{array}{c}-0.015^{* * *} \\
(0.004)\end{array}$ & & & & \\
\hline I4 & & & & & & & $\begin{array}{c}-0.017 * * * \\
(0.004)\end{array}$ & & & $\begin{array}{c}-0.017 * * \\
(0.006)\end{array}$ \\
\hline Largely & & & & & & & & $0.281^{* * *}$ & $0.080 * *$ & 0.009 \\
\hline Unregulated & & & & & & & & $(0.032)$ & $(0.036)$ & $(0.039)$ \\
\hline Broadly Regulated & & & & & & & & $\begin{array}{c}0.199 * * * \\
(0.021)\end{array}$ & & \\
\hline Highly Regulated & & & & & & & & $\begin{array}{c}0.207 * * * \\
(0.035)\end{array}$ & & \\
\hline Intercept & $\begin{array}{c}0.230 * * * \\
(0.015)\end{array}$ & $\begin{array}{c}0.230 * * * \\
(0.015)\end{array}$ & $\begin{array}{c}0.230 * * * \\
(0.014)\end{array}$ & $\begin{array}{c}0.230 * * * \\
(0.013)\end{array}$ & $\begin{array}{c}0.230 * * * \\
(0.013)\end{array}$ & $\begin{array}{c}0.230 * * * \\
(0.013)\end{array}$ & $\begin{array}{c}0.230 * * * \\
(0.011)\end{array}$ & & $\begin{array}{c}0.202 * * * \\
(0.018)\end{array}$ & $\begin{array}{c}0.221^{* * *} \\
(0.015)\end{array}$ \\
\hline Observations & 26 & 26 & 26 & 26 & 26 & 26 & 26 & 23 & 23 & 23 \\
\hline R-squared & 0.099 & 0.129 & 0.263 & 0.364 & 0.306 & 0.314 & 0.504 & 0.909 & 0.194 & 0.570 \\
\hline
\end{tabular}


Table 7: Dependent variable is the unexplained part of the Melly 90th quantile wage gap (working sample)

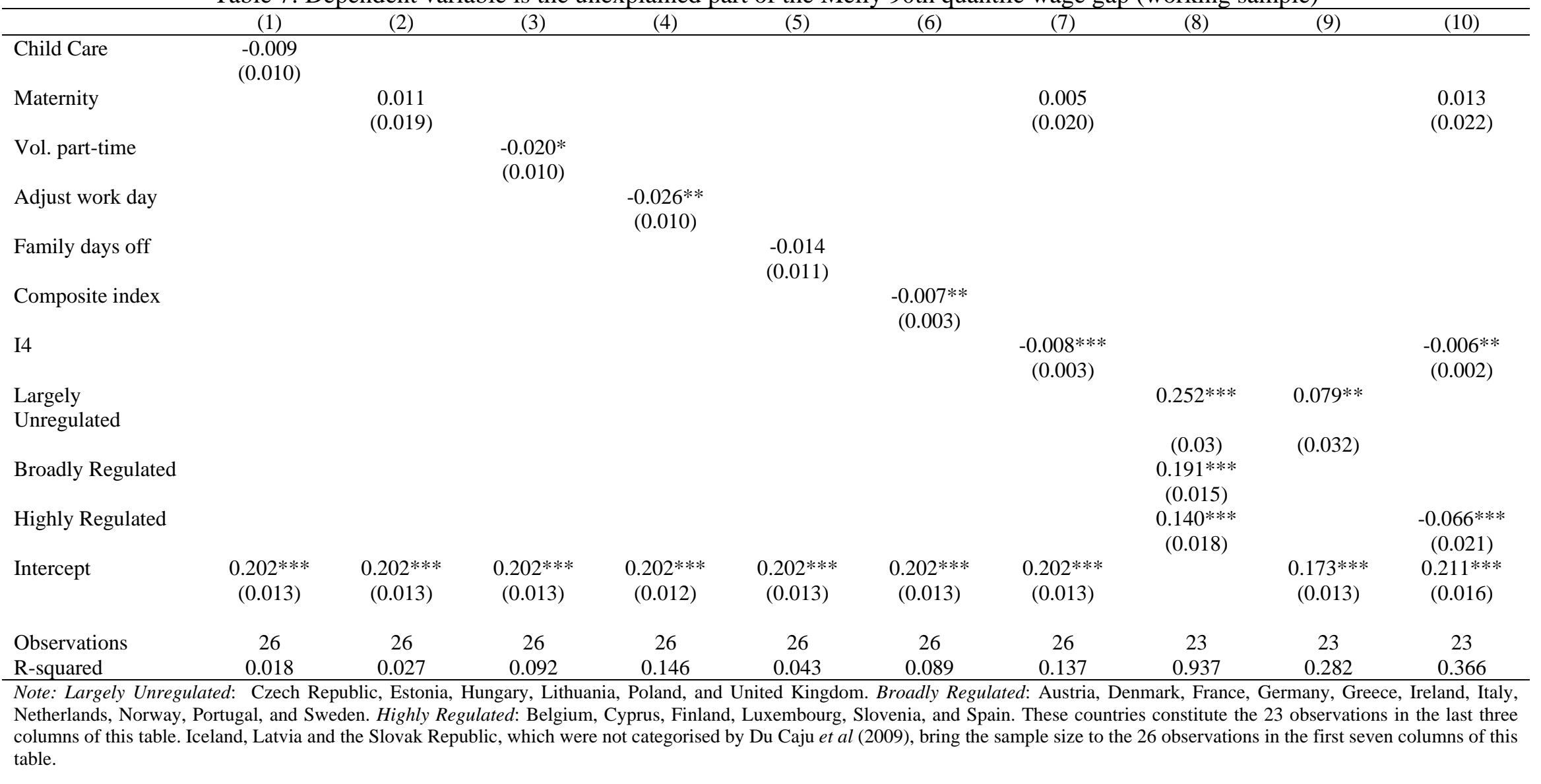

